\title{
Designing Mars Missions for the Utilization of Rotorcraft
}

\author{
Michael T. Radotich ${ }^{1}$, Zarya O. deSouza ${ }^{2}$, Sophie R. Gelhar ${ }^{3}$, Henry D. Gallagher ${ }^{4}$, Shannah N. \\ Withrow $^{5}$ \\ $\left({ }^{1}\right.$ Alaska Space Grant Consortium, ${ }^{2}$ Missouri Space Grant Consortium, ${ }^{3}$ Wisconsin Space Grant \\ Consortium, ${ }^{4}$ Science Technology Corporation, ${ }^{5}$ Ames Research Center) Moffett \\ Field, CA, USA
}

\begin{abstract}
Following the technical demonstration of the Mars Helicopter on the Mars 2020 mission, interest in further exploration of Mars utilizing rotorcraft is expected to increase. Previously, scientific exploration has been limited by the resolution of instruments on satellites and the terrain a rover can traverse. Rotorcraft enable exploration in previously inaccessible locations with increased efficiency compared to rovers and improved resolution (compared to satellites). This paper describes missions designed to utilize the unique capabilities of rotorcraft in order to advance the science performed extraterrestrially. For Mars this includes tasks such as determining if Mars ever supported life, understanding climate processes and history, determining the evolution of Martian geology, and preparing for human exploration. The missions fall into three general categories: rover assistance, sample collection, and data collection. Complimentary concept vehicles are also discussed. This paper is meant to serve as a reference, resource, and starting point for the future exploration of Mars with rotorcraft.
\end{abstract}

\section{Introduction}

The 2020 Mars Helicopter, if successful, will be the first flight on another planet and will expand the potential of extraterrestrial exploration. With the first extraterrestrial flight in mind, the scientific community has already begun the planning stages for future missions on Mars with aircraft. However, the task of designing rotorcraft capable of successfully and efficiently traveling through extraterrestrial atmosphere remains a daunting challenge. Mars is a prime example of an environment vastly different from Earth's with a unique atmospheric composition, and temperature range in addition to different navigational requirements and gravitational acceleration.

The Planetary Science Decadal, the standard guideline for future space research, lists four science goals that drive the design of future Mars rotorcraft missions [1]. The life goal aims to continue the search for extraterrestrial life, search for habitable biomes, and define what is needed to support life as a whole. The climate goal aims to observe the atmospheric makeup, define the different life stages of the planet's environment, and determine what outside forces led to the Martian climate found today. The geology goal aims to define the events that shaped the planet, discover how the planet changed physically over its timeline, and model the modern day volcanic, seismic, and tectonic activities. The human exploration goal aims to prepare for human missions on Mars by 
planning for human exploration of the orbit, the surface, on the moons Phobos and Deimos, and finally creating a sustained presence on the surface of Mars. These four goals provide the basic scientific justification and are a required element for any missions to be approved.

The use of rotorcraft for planetary exploration potentially enables a larger breadth of locations for Martian investigation. Previously proposed locations eliminated due to engineering concerns can be re-evaluated with fewer constraints.

\section{Literature Review}

This section summarizes current knowledge of the Martian environment and factors that impact the designs of future Mars missions and their corresponding rotorcraft. This knowledge is vital in Mars rotorcraft design as atmospheric conditions are significantly different than what can be found on Earth.

\subsection{Flight on Mars}

Flying on Mars has numerous challenges that must be addressed, starting with the density of the atmosphere. The Martian atmosphere has a pressure ranging from 4.0 to 8.7 millibars, averaging at 6.36 millibars at the mean radius, $0.6 \%$ the pressure of earth's atmosphere [2]. The low-pressure results in a low air density of 0.02 kilograms per square meter compared to Earth's 1.225 kilograms per square meter. The low density is a significant problem, as rotors obtain their lift from the flow of the fluid over a surface, such as an airfoil. In order to compensate for thin air, rotor blades require a large surface area and must operate at much higher RPMs to achieve usable thrust than on Earth. Higher RPMs, coupled with a 240 meters per second speed of sound compared to Earth's 340 meters per second [3], put the rotor tips in danger of approaching the speed of sound. Breaking the speed of sound results in a loss of lift and creates destructive vibrations in the rotor, making it impossible for rotorcraft to fly with rotor tip speeds at or above the speed of sound. 


\subsubsection{Atmosphere}

\section{Martian Atmosphere Composition}

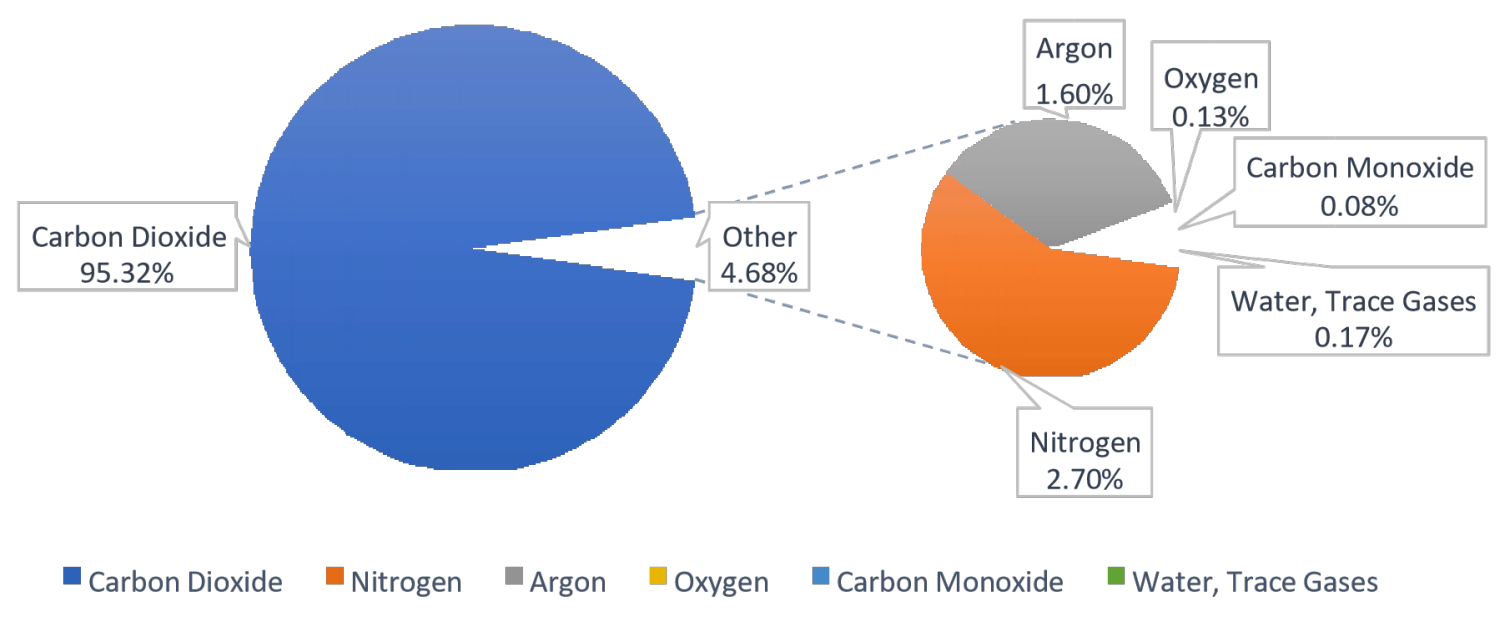

Figure 1: Martian Atmospheric Composition

The Martian atmosphere [F1] is composed of mostly carbon dioxide with small amounts of other gases, as shown in Figure 1. Because of the relatively small percentage of oxygen, internal combustion and turbine engines, the power plants of most large aircraft on Earth, are not feasible for the Martian atmosphere. Any aircraft on Mars would need to run on either solar or nuclear energy to be considered viable. Nuclear power sources currently face weight constraints but may be viable in the future. Battery powered rotorcraft capable of solar recharging are currently feasible and appear to be the logical option, but as on Earth, they will run into scaling issues as the size of the aircraft increases.

Mars's surface temperature can range from -140 degrees $\mathrm{C}$ at the poles up to 30 degrees $\mathrm{C}$ during the day on the equator [4], creating a significant temperature range for the proposed vehicles to endure. Mars also experiences extreme localized temperature variance; at night on the equator, the warmest segment of Mars, the temperature can drop as low as -80 C [5]. If using a battery powered rotorcraft, it is important to keep the battery insulated from these extreme temperatures. For example, low temperature lithium batteries operate between -50 and 40 degrees C [6]. In order for batteries to survive even equatorial nights they must have sufficient insulation and/or heating. 
Temperature must also be taken into consideration for electronic component and structural material selection.

\subsubsection{Gravity}

One of the main beneficial differences of Martian flight is the reduced effects of gravity. Mars has a gravitational acceleration of $3.71 \mathrm{~m} / \mathrm{s}^{2}$ [2], almost a third of Earth's $9.81 \mathrm{~m} / \mathrm{s}^{2}$. Lower gravity aids in flight and helps offset the problems caused by the low-density atmosphere. Though the gravity is lower, and less thrust is required to fly, the centrifugal forces on the spinning blades and inertia of the aircraft remain unchanged.

\subsubsection{Navigation}

On Earth, unmanned aerial vehicles utilize GPS for navigation. Since Mars does not have GPS architecture in place and will not have one for the foreseeable future, a different system will need to be used for navigation. The Curiosity rover navigates in three primary modes. The first mode is blind navigation, where exact maneuvers are given by a team on Earth. The rover then performs these maneuvers, keeping track of its movement through wheel odometry. This method introduces great amounts of uncertainty, especially over long distances. The second mode, auto- navigation, reaches a pre-determined waypoint using a level of autonomy. The rover pauses to take pictures periodically and uses obstacle avoidance algorithms to determine the safest path. In the third mode, visual odometry is also implemented in addition to obstacle avoidance. Visual odometry compares pictures taken at a known time difference to determine movement characteristics. The third mode is the slowest and safest method to account for wheel slips in the sand that add uncertainty to wheel odometry [7].

Limited in battery life, rotorcraft do not have the time to hover for long periods to pick and choose their route if efficient progress is to be made. If the aircraft is equipped with a radar or LIDAR mapping system, it can compare its data to existing satellite elevation data to determine its position. Another option, inertial navigation (accelerometers, speed, and distance sensors) can be used alone or in conjunction with visual odometry to determine position. If the area of travel is small enough, surface radio transmitters deployed upon atmospheric entry can triangulate the aircraft's position, allowing it to navigate. 


\subsection{Planned Rotorcraft Missions}

\subsubsection{Mars Helicopter}

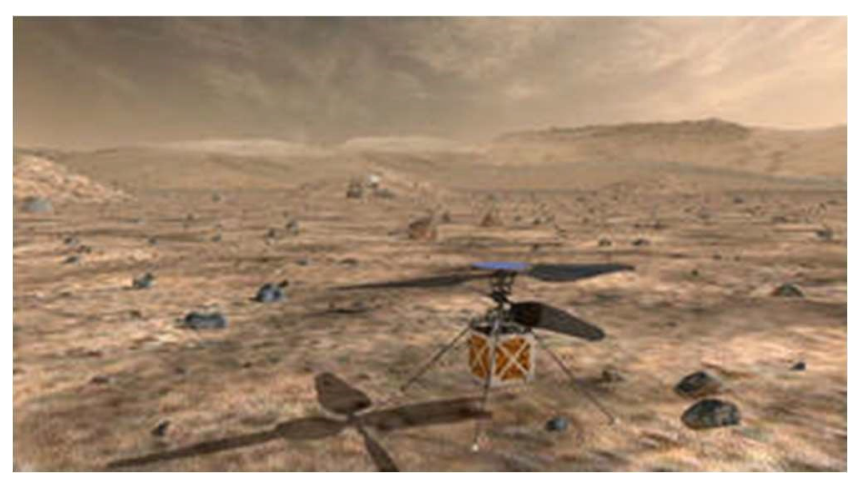

The Mars Helicopter [F2], sponsored by JPL, is part of the Mars 2020 mission as a technology demonstrator for extraterrestrial flight. The coaxial design has a rotor diameter of 1.21 meters with collective and cyclic control on both rotors and a maximum

RPM of 2800. The helicopter has a

Figure 2: Mars Helicopter

maximum mass of 1.8 kilograms, with all systems directly contributing to the helicopter's flight. The technology demonstration mission is designed to last for 30 sols with ten 90 second flights scheduled throughout that period. The short flight time is due to limited battery capacity, as half of the battery capacity needs to be used to keep the helicopter systems warm during the frigid Martian nights [8]. The capabilities and limitations of the Mars Helicopter's design helped to guide the mission and vehicle concept development processes.

\subsubsection{Dragonfly}

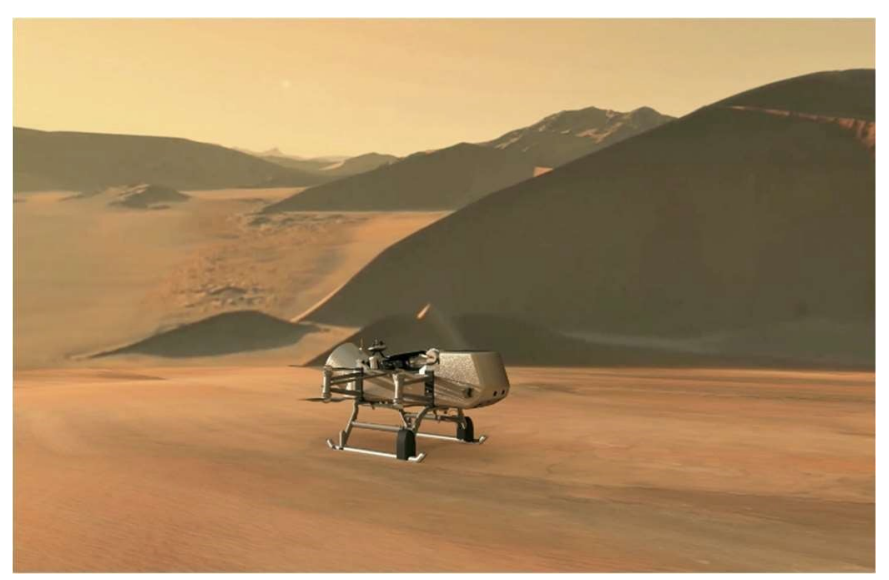

Figure 3: Dragonfly Concept
Part of NASA's New Frontiers program and sponsored by the Johns Hopkins Applied Physics Laboratory, Dragonfly [F3] is a rotorcraft mission meant to explore Saturn's largest moon, Titan, and is set to launch at the end of 2025. Current Dragonfly vehicle concepts have a dual- quadcopter design with large landing skids beneath it. Unlike flight on Earth and Mars, Dragonfly benefits from Titan's lower gravity (about $1 / 7^{\text {th }}$ that of Earth) and higher density atmosphere (four times the density of Earth at sea level) to make unmanned flight the preferred traveling method. Capitalizing on this, the craft is designed to accommodate a suite of instruments including the Dragonfly Mass Spectrometer, Gamma-Ray and Neutron Spectrometer, Geophysics and Meteorology Package, and Camera Suite [9]. It will spend its two- year mission making flights to different points of interest and collecting data using its 
recording instruments. While this mission has different flight constraints than the missions developed below, its quadcopter design, multirotor system, and instrument utilization were all used as inspiration.

\subsection{Mars Science Goals}

The 2013-2022 Planetary Science Decadal [1] cites Mars as an important target for future research missions. Mars research can be categorized as four broad scientific goals for future missions to advance: life, climate, geology, and human exploration [10]. These goals each have their own objectives. Each mission described in this paper is applicable to at least one science goal. The following sections are derived from the Planetary Science Decadal (2.3.1-2.3.3) [1] and the 2018 version of the Mars Science Goals, Objectives, Investigations, and Priorities document by the MEPAG Goals Committee (2.3.4) [10].

\subsubsection{Life}

Discoveries of methane and dry water features suggest Mars may have held extraterrestrial life, but without distinct evidence, it is only a theoretical probability. The purpose of this goal is to determine if life ever arose on Mars and, if so, to craft a narrative of its evolution with the surface climate. Discovery of biological life on Mars, past or present, could offer insight into evolution patterns and could help to predict future extraterrestrial discoveries on other planets. If life is not discovered, then it will still provide valuable information about what is necessary to cultivate life beyond CHNOPS (carbon, hydrogen, nitrogen, oxygen, phosphorous, and sulfur) requirements. The primary objectives are:

- Discover accessible sites that offered the greatest potential for supporting life and how the current habitation requirements - past or present liquid water sources, energy availability, physiochemical factors (i.e. $\mathrm{pH}$ and temperature, and biogenic element availability) - varies between these sites.

- Discover which accessible sites have the greatest preservation potential and could hold proof of past extraterrestrial life or biomes. Determine what major factors affect the ability to preserve these planetary landmarks.

- Determine how orbital and galactic evolution played a role in modifying habitability, both on a local and planetary scale. 
- Determine the existence of currently habitable sites and what significant atmospheric and visual signs denote these sites (i.e. what can be observed via satellite and off-site sensors) so a criteria can be created for future planetary exploration.

\subsubsection{Climate}

Martian climate conveys an important narrative because the timeline of the planet's climate has important implications for the future of Earth. Martian climate has been divided into three time periods: ancient, recent past, and modern. Characterizing these three distinct periods is important because it is important to understand how the planet's changing obliquity (the tilt of its polar axis) affects the pressure, temperatures, and survivability of water on the surface. This characterization also helps to understand the planet's dust, carbon dioxide, and water cycles. Understanding the characteristics of Martian atmosphere will be critical to future mission design. The primary objectives of this goal are:

- Determine what factors control the variations in climate by mapping the wind structures and dissecting the planet's current dust, carbon dioxide, and water cycles.

- Catalog what chemical species can be found in the atmosphere and at what concentrations, comparing them to predicted models. Determine the current level of accuracy of these models while also tracing their paths to determine the sources and sinks of these atmospheric aspects. See what affect aerosols and volcanic activity have on the atmosphere's composition as well as the impact of photochemical reactions on creating these atmospheric compositions.

- Create a timeline of Martian climate changes to pinpoint any observable changes over relatively small periods of time (i.e. 10 - 1,000 year timescales), characterize the events that contributed to these changes, and determine the atmospheric changes that created and supported the carbon dioxide ice cap.

- Calculate the impact Martian orbital and obliquity variations have on the climate, particularly with regards to its water cycle, and create a historical narrative for the polar features, such as its latitude-dependent ice mantle and polar layered deposits.

- Model the ancient climate stage for Mars, determine if it could have supported liquid water for extended timespans, and determine what particular processes could have made this possible. 
- Determine the reasons and methods that caused Mars to experience the atmospheric change from its ancient stage to its current one and pinpoint the processes that control the outgassing of the atmosphere.

\subsubsection{Geology}

The evolution of the Martian landscape, such as its canyons and inactive volcanoes, is an important subject of study because the global evolutionary processes are still visible in its geological features. The surface of Mars is dotted with old lakebeds and preserved carbonates, suggesting the ancient version of Mars was less acidic and may have supported liquid water. Subsurface Mars, because of its separation from the harsh atmosphere above, could contain preserved or existing environmental biomes capable of supporting biological organisms. Creating a detailed image of the planet's internal structure, dynamics, and evolution is also important to creating an accurate profile of Martian geology. The key objectives for this goal are:

- Determine the timeline and causes for the variances in Martian environment and determine if any periods were habitable. Research the time periods when each of the diverse sedimentary layers formed as well as the origins of the regolith.

- Seek out preserved carbon compounds and, if found, record the geological location of origin. Use this information to model the Martian carbon cycle and pinpoint the origins of recorded methane spikes and abnormalities.

- Determine the formation origins and characteristics of the igneous rocks found on the surface and utilize the information to learn about the crust and mantle processes as well as how the Martian core formed.

- Develop a working model for Martian geology over the course of its climate change by sampling polar layered deposits and sedimentation and mapping out the evolution of the Martian crust. Find how Martian meteorites, interior structure, and plate tectonics fit into this geographical timeline.

- Pinpoint the time period and history of the end of activity in the Martian core, known as its dynamo, and research how this influenced the internal structure, magnetic field, and operation of the heat-flow mechanisms.

- Discover the present-day Martian seismic, tectonic, and volcanic activity. Determine how these activities can be used to develop an accurate model of the current internal and 
external structure and how these features have an impact on habitability, atmosphere, and magma movements.

\subsubsection{Human Exploration}

This goal aims to utilize the consolidated data from other narratives to achieve a human presence on Mars and within its orbit. To preserve the safety of human explorers on Mars, exploration is planned in four steps: prepare for exploration in Martian orbit, exploration on the surface of Mars, exploration on either Martian moon (Phobos or Deimos), and a sustained human presence on the surface of Mars. Since each step builds in succession, the information becomes more in- depth as the stages progress. The key objectives for each step are:

- Exploration of Martian Orbit - Obtain sufficient knowledge to design a manned mission for humans within Martian orbit.

- Examine the atmospheric effects on flight conditions entering Martian orbit from deep space.

○ Determine aspects of the atmosphere that will affect aerobraking.

- Research upper Martian orbit features that impact the delivery of crew and cargo.

- Exploration of the Martian Surface - Obtain sufficient knowledge to design a manned mission for humans on the surface of Mars.

- Study the atmospheric effects on entry, descent, and landing (i.e. electricity or radiation)

○ Research biohazards present at landing sites or exploration zones and how those hazards could endanger the crew or contaminate samples intended to return to Earth.

- Determine the environmental areas that fall under the protection of the Committee on Space Research's "Special Region” mandate (i.e. an area holding a high potential to contain Martian organic life forms).

- Test the resilience of life support gear and tools against Martian atmospheric conditions.

- Determine if there are hazards at the landing site that could affect landing or traversal.

○ Determine the dangers presented to the hardware and crew's health and 
performance by characterizing the ionizing radiation in the environment and health impacts of the regolith and dust storms.

- Exploration of Phobos/Deimos - Obtain sufficient knowledge to design a manned mission for humans on the surface of Phobos and/or Deimos.

- Understand the geological and geophysical composition while pinpointing any available resources.

- Understand the atmospheric conditions present on the surface and in lower orbit.

- Sustained Presence on Martian Surface - Obtain sufficient knowledge to design a manned mission for humans to maintain occupation on the surface of Mars.

- Test the resilience of life support gear and tools against Martian atmospheric conditions.

- Characterize potential sources of extractable water significant enough to be utilized for long-term human needs.

\subsubsection{Crosscutting Goals}

These goals have multiple commonalities and often a success in one goal is also beneficial to another. Many of the described missions help to forward multiple goals, and many individual objectives are interdependent. However, only the primary goals impacted by the described mission are listed as a scientific justification in the Section 3 missions.

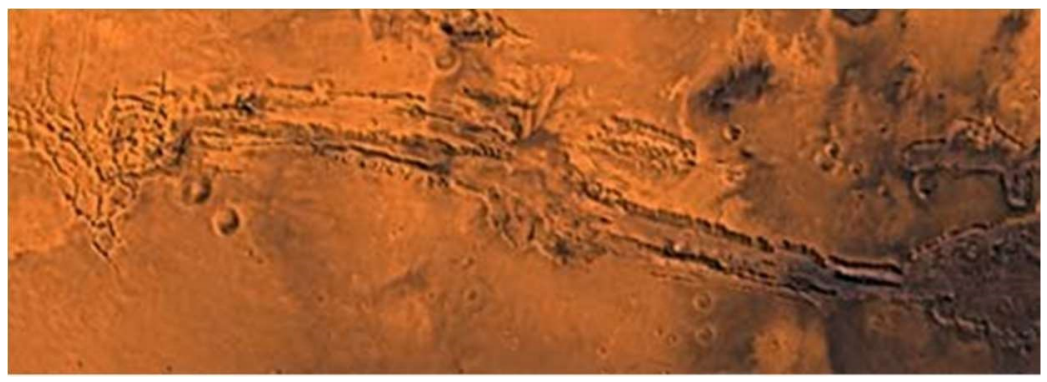

Figure 4: Valles Marineris

2.4 Exploration Site Selection Site selection for Mars exploration is a multi-step process with two main considerations: scientific objectives and engineering constraints. Every time a new mission is proposed, there are usually three to four site selection workshops and over one hundred people who contribute. Engineering constraints (i.e. elevation, latitude, slopes, and rock height) are the priority as the scientific merit of a site cannot be determined if the instruments cannot land there. At the workshops, small groups of scientists propose sites, and the entire selection committee ranks the sites based on scientific merit and if it met the engineering constraints. The committee also 
categorizes the sites into "Land On" and "Go To" to describe if the science location is viable for landing. Between meetings, satellite data of high priority sites is obtained. The goal of these workshops is to narrow down the site list to three to five sites for NASA Headquarters, who will ultimately choose the site where the vehicle will land [11]. The selection committee sends a letter with a short discussion of the differences between the sites and emphasizes the preferred selection [12]. Valles Marineris [F4] was one of the sites considered for the Curiosity landing site and the Mars 2020 site. During the Curiosity site selection process, multiple locations inside Valles Marineris were proposed, but all were eliminated before the short list was proposed to NASA Headquarters because of concern about the terrain, even though the sites met the engineering constraints [11]. During Mars 2020 site selection, advancements in navigational systems (entry, descent, and landing) and higher quality satellite data enabled multiple locations inside Valles Marineris to be reconsidered [13] and one, an area known as Melas Chasma, progressed to the short list but was not the primary choice. In this instance, another location with more rock sample diversity per unit of area was preferred over Melas Chasma [12]. Rotorcraft on Mars would eliminate some engineering constraints so more diverse sites can be safely chosen for future missions.

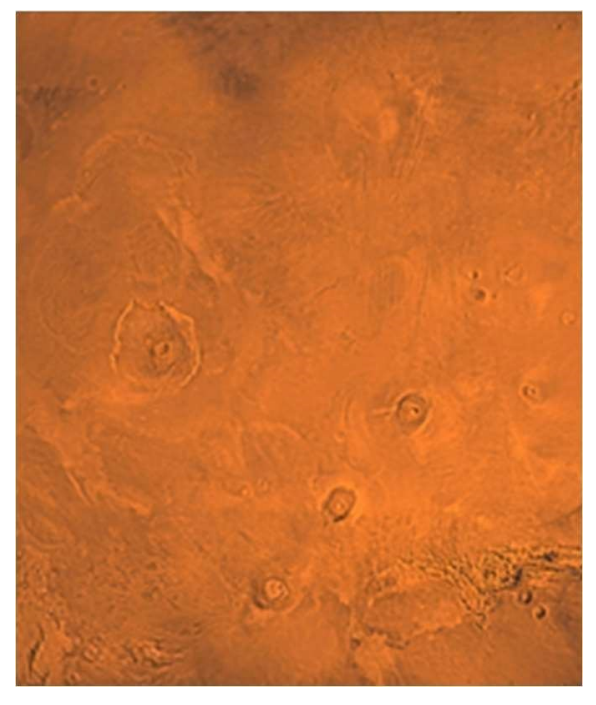

While about 50 sites are considered for each Mars mission, many areas in violation of current engineering constraints are not proposed but could be considered with the advent of Martian rotorcraft. Arsia Mons, for example, has generated interest for its skylights and possible underground environment access. The Tharsis Volcanic Region of Mars is home to three main shield volcanoes: Arsia Mons, Pavonis Mons, and Ascraeus Mons. While all are now extinct, previous volcanic activity created interesting features in the landscape around the volcanoes. The THEMIS instrument onboard the

Figure 5: Tharsis Volcanic Region Mars Odyssey satellite has spotted seven skylights on the slopes of Arsia Mons, possibly evidence of caves formed from lava flows in Mars's past. THEMIS can see caves facing skyward with a diameter of more than a hundred meters and only determine if the depth is greater than one hundred meters [14], so there may be more evidence of caves that cannot be 
captured by this instrument. These caves could contain traces of past or current biological life and may be ideal in providing shelter for future manned missions.

Over the course of three years, opinion on the scientific merit of cavern exploration changed dramatically. In 2007, Cushing et al. [14] proposed the caves are not worth exploring in more depth. Caves could provide protection from the hazards of the Martian atmosphere, but they also pose sufficient risk since not much is known about the atmosphere and geology of the interior areas. The Tharsis region is at high elevation, so any explorative vehicles would be required to spend time ascending the volcanoes, and it is contended whether past Martian life could have migrated up to those elevations. Since THEMIS can only see the skylight aspect of the cave, scientists are not sure if the skylight is a cave or just a shaft. If it is only a shaft, it is possible the sun would have burned away any life and biosignatures found on the shaft floor and walls [14].

Eventually in 2010, investigation into the similarities between caves on Earth and Mars sparked new interest in Martian caves. Studying lava tubes will help in understanding the history and evolution of volcanism and global heat flux. Also, since caves on Earth harbor many types of life, it is reasonable to assume Martian caves could harbor current or extinct life forms. Inside the caves, past biosignatures would have been protected for future discovery [15]. Williams et al. [16] modeled the lifetime of ice in caves on the Martian surface. They specifically investigated water ice growth instead of carbon dioxide ice for water extraction purposes. Areas where water ice is sustained would be areas of astrobiological importance and potential future water sources for human exploration missions. The model assumes water ice is formed by frost deposition, a process where water vapors change directly into solid ice without passing through the liquid phase. The results of the simulation showed conditions in a Tharsis region cave would support water ice formation; in fact, the region is one of the best locations for water ice growth on Mars [16]. The high probability of water ice increases the scientific merit of the site for research of the Martian past and preparation for a future human presence.

Landing site selection is an important component of the Mars mission design process. Previously, rover engineering constraints eliminated many scientifically intriguing sites discovered through satellite research. Even sites that met the engineering constraints were eliminated due to rover limitations such as traversal speed. With the introduction of Martian rotorcraft, some of the 
engineering constraints limiting site selection are no longer considered, enabling new methods of research in previously inaccessible regions.

\section{Missions}

\subsection{Rover Assistance}

\subsubsection{Pathfinding and Sample Transporting Support}

This mission features one or two rotorcraft acting as support for rover and lander operations. One rotorcraft acts as a scout with the rover as a base. The main purpose of the other rotorcraft is to transfer samples between the rover and another location, such as a cache or lander.

\subsubsection{Science}

The purpose of the Rover Assistance mission is to increase the efficiency of ground operations on Mars. As these aerial vehicles are designed to be dependent on the rover, their science goals are directly linked to the rover's missions. The Mars 2020 rover has the mission of traveling to a location to collect samples before returning the samples to a designated cache [17]. The rover will then be able to continue on to a new location to collect more samples to bring back to the cache. With the assistance of a transport rotorcraft, the rover would not have to spend the resources required to travel back to the cache, increasing the number of samples obtained in a period of time. The vantage point a pathfinding rotorcraft could provide would help with hazard avoidance, reducing the risk of damage or immobilization of the rover while driving on Mars. The rotorcraft could also provide "housekeeping" services as the rotors can produce gusts to clean solar panels, increasing the lifetime of a solar-powered rover.

\subsubsection{Mission Statement and CONOPS}

The Rover Assistance program shall utilize air vehicles to aid in rover operations. This mission includes transferring samples from the rover to the lander, scouting the landscape for the rover, and performing basic maintenance procedures for the rover and lander. The objectives of the mission are to enable sample collection over a large area, decrease resources spent by the rover to return samples to land based vehicles, and extend mission lifespan.

A Rover Assistance mission would involve four vehicles: two rotorcraft, a rover, and a lander. An example operation for this mission would start with the smaller scout rotorcraft taking off from the rover to scout the area. The scouting information would provide a different vantage point for the 
rover to scout for the best place to collect samples and decrease the risk of driving into a hazardous area. After completing the preprogrammed flight path, the scout rotorcraft would land near or on the rover and transmit the scouting data. The rover can then perform its instructions after communicating with Earth. The larger transport rotorcraft would then take off from the science base lander and autonomously fly to the rover, pick up the samples, and return to the lander. The rotorcraft charges after the samples are transferred to the lander.

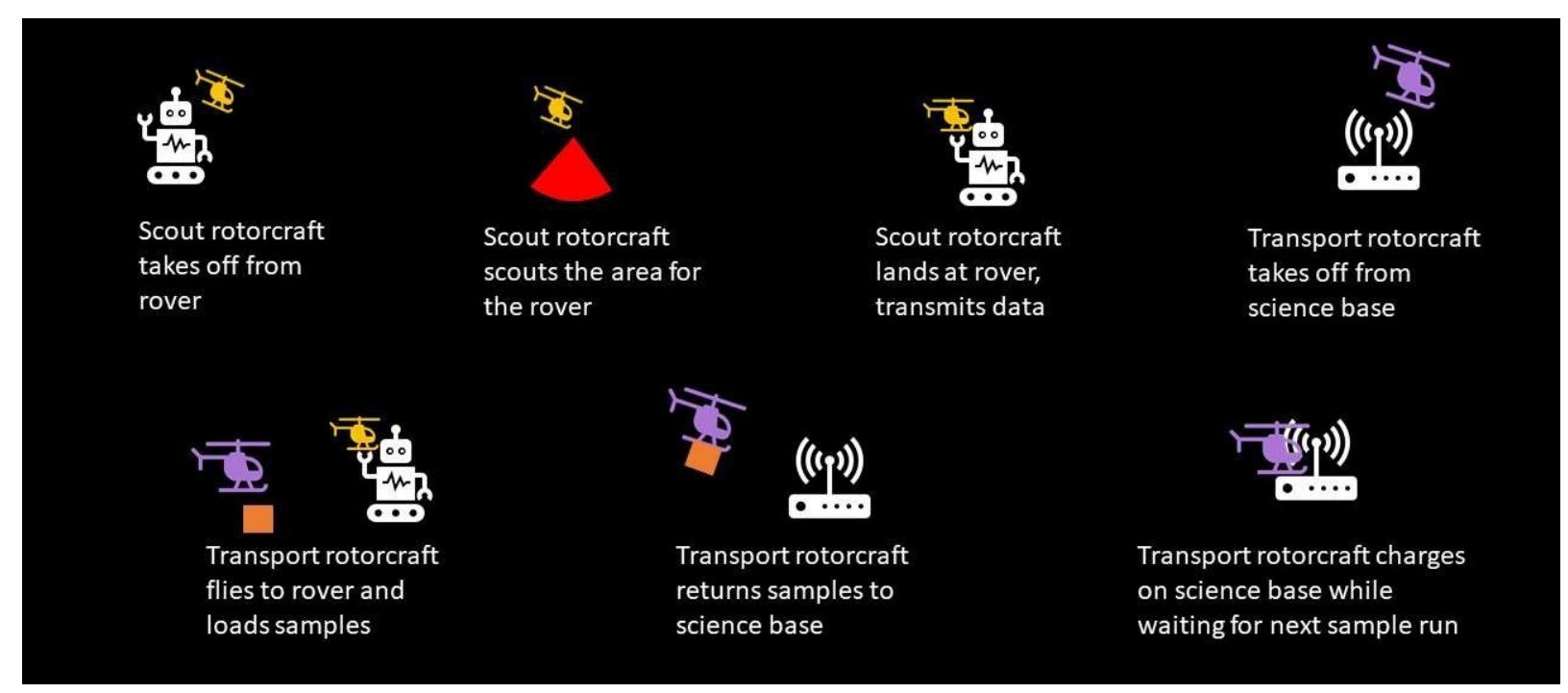

Figure 6: Pathfinding and Sample Transporting Support-CONOPS graphic

\subsubsection{Possible Challenges}

There are multiple considerations regarding the Rover Assistance mission. The first is communication between the vehicles and Earth. The lander, being the main vehicle, would have communication equipment for uploading and downloading information from Earth through the satellites. The rover would communicate with the lander directly. The advantages of installing Earth communication equipment directly onto the rover as well is that the rover could travel farther and be outside of the lander's line of sight. Then, the range of the rover would be determined by the transport rotorcraft's chosen range and operational limits (i.e. whether the rotorcraft stays one flight distance away from a land-based vehicle). Communication from Earth to the scout rotorcraft would be relayed through the rover to reduce communication equipment weight on the rotorcraft. The transport rotorcraft would need to communicate with the lander and the rover since it would be traveling between the two. To keep the rotorcraft from having to allocate weight to communication devices, 
the transport rotorcraft would likely only be capable of communication with Earth through the lander or the rover.

The next consideration is whether two rotorcraft would be needed for this mission. The operations performed by the scout rotorcraft could potentially be executed by the transport rotorcraft. Only

having a single rotorcraft would occupy less space in the aeroshell, but that rotorcraft would have more tasks and take on more risk. The rotorcraft would travel to the rover to scout before the rover collects the sample and wait for the sample to be collected before traveling back to the lander. This would also reduce the rover's field of vision while the rotorcraft is traveling or away at the lander. Additionally, added complexities include the transport rotorcraft needing to interact with both the lander and rover while transporting samples. If the rover deposits the cache of samples for the rotorcraft to pick up, the interaction between vehicles would be minimal. Depending on the design of the lander, the transport rotorcraft may land on the science base to deliver the sample and recharge. If the lander has a robotic arm, the sample cache could be dropped close to the lander within range of the arm. Since the lander is immobile, the rotorcraft would have to be accurate in its placement of the cache so the rotors do not damage the lander.

\subsection{Sample Collection}

\subsubsection{Rock Sample Collection}

Since the cornerstone of the Mars 2020 mission is the ability to prepare and collect samples, rock sample collection is seen as a viable way to investigate Mars. Unlike the Rover Assistance mission, where rotorcraft aid in the sample collection done by the rover, this mission focuses on eliminating constraints associated with the rover by using vertical flight.

\subsubsection{Science}

The science goals achieved by the Rock Sample Collection mission are similar to the Mars 2020 missions of seeking past microbial life, looking for evidence of ancient habitable environments where microbial life could have existed, studying the rock record to reveal more about the geologic processes, and monitoring environmental conditions so mission planners understand better how to protect future human explorers [18]. The difference, however, is that the proposed mission can efficiently cover previously unreachable territory. This mission is tied to the life goal since it can focus on areas with a high probability of harboring life. The geology goal is also relevant as the 
vehicle would be collecting rock samples. Canyons provide interesting subjects for rotorcraft rock sample collection since the walls expose multiple rock layers that rotorcraft, unlike rovers, would be capable of accessing.

Typically referred to as the "grand canyon of Mars", Valles Marineris has yet to be explored by ground vehicles despite proposals as a landing site for both Curiosity and Mars 2020. Valles Marineris, an active geology canyon, experiences rockslides and marsquakes, potentially uncovering new rock layers [19]. The possibility of accessing an area with rockslides unlocks the ability to access deeper layers of the crust for geological analysis. Many rock samples retrieved close to the surface have been severely damaged by the radiation and photochemistry as a result of the thin atmosphere. The canyon is known to have been formed by tectonic activity, but evidence suggests precipitation could have made significant contributions to shaping the feature, increasing the scientific merit of the area [20].

While choosing the Curiosity landing site, Valles Marineris was considered as a possible landing site multiple times. Ultimately, the selection committee was concerned about the rocky landing and the long traversal required to reach the desired wide variety of rocks [11]. A sample collection rotorcraft would not face the difficulty of driving over the harsh rocky terrain, negating these concerns. The last aspect eliminating Valles Marineris as a landing site was the possible risk of slope winds near the canyon wall, something to evaluate during rotorcraft design and testing. When choosing the landing site for the Mars 2020 rover, Melas Chasma, the widest section of the Valles Marineris canyon, was proposed as a possible landing site. It was again eliminated because satellite images showed less rock diversity over the same area when compared to Jezero Crater. In addition, Melas Chasma was a "Go To" site instead of the "Land On" site of Jezero Crater [12]. Utilizing rotorcraft would solve the issue of the rock diversity being more spread out by reducing the travel time and making longer excursions more viable. One issue with collecting rock samples near the canyon walls, however, is the possibility of shadows preventing solar panel charging on the rotorcraft. The vehicle would have to be designed to store enough power to fly to someplace it could charge before collecting the rock sample.

\subsubsection{Mission Statement and CONOPS}

The Rock Sample Collection mission shall utilize air vehicles to aid in rock sample collection in previously inaccessible locations. 
The objectives of the mission are to enable rock sample collection in canyons, riverbeds, and the poles, and to decrease sample return time to a land-based vehicle. The canyons, riverbeds and poles have not been accessed by land-based vehicles yet due to risk of large rocks, steep slopes, cold temperatures and long traversal time.

A Rock Sample Collection mission would involve two vehicles: a lander and a rotorcraft. An example operation for this mission would start with the rotorcraft taking off from the lander and autonomously flying to a predetermined location. It would land and begin to collect a sample. If the rotorcraft is in a sunny location, it will charge with solar panels while the sample is collected. If not, the rotorcraft will relocate to the nearest sunny location to charge. The charged rotorcraft with the sample would take off to return to the lander. The lander will have the science equipment necessary to analyze the samples and store them for later retrieval. The rotorcraft would land on or near the lander and the lander would collect the sample from the rotorcraft. The lander would then reload the rotorcraft sample collection device, so it can obtain another sample.

The rotorcraft will charge and communicate with Earth to download its next flight path.

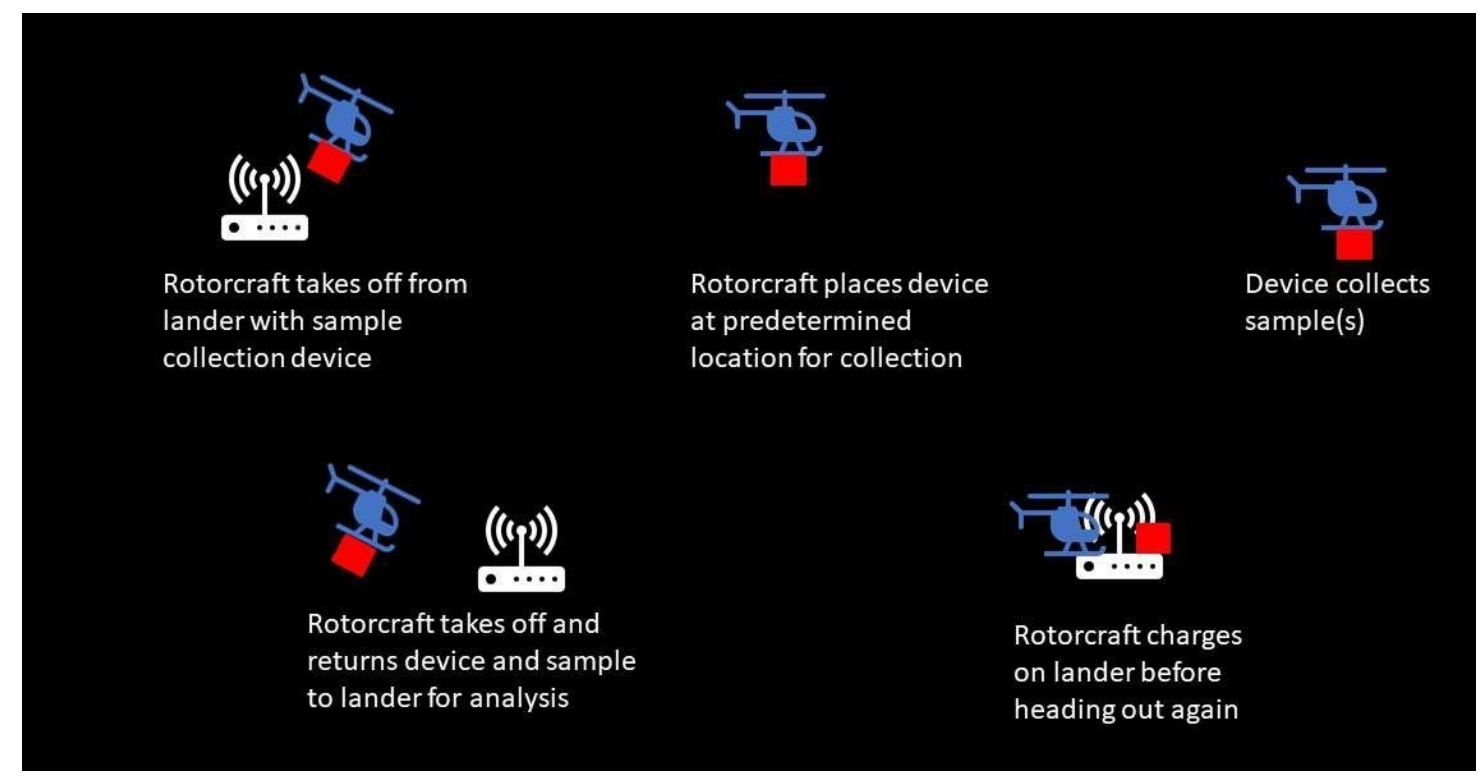

Figure 7: Rock Sample Collection-CONOPS graphic 


\subsubsection{Possible Challenges}

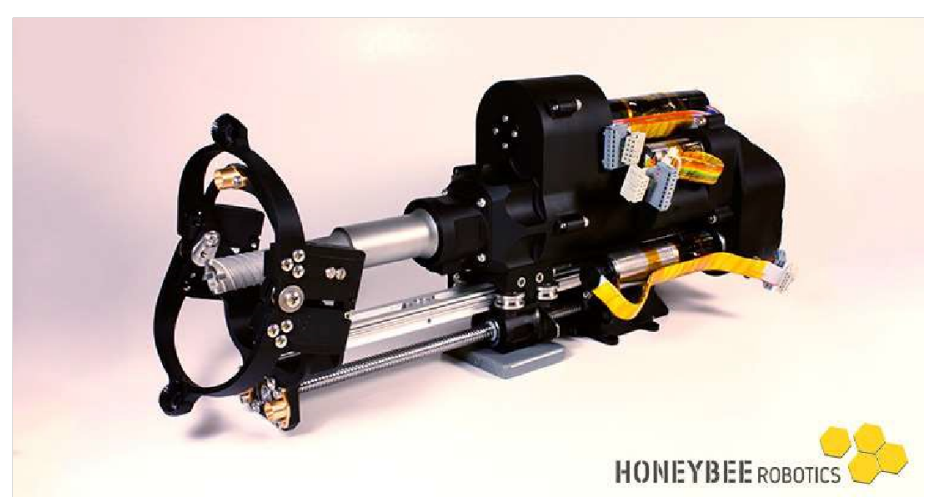

Figure 8: ROPEC Drill

One of the challenges with the Rock Sample Collection mission on Mars is choosing the sample collection instrument. Currently, Mars rock samples are collected by a percussive drill mounted on the robotic arm of the Mars 2020 rover. The ROPEC drill [F8], designed by Honeybee Robotics, was

built to be mounted on a rover robotic arm the size of MER's arm before the decision was made for Mars 2020 to be the size of Curiosity [21]. The resulting design produced a lightweight drill weighing in at only four kilograms. The percussive action of the drill is used to collect rock core samples from a wide variety of rock types. The drill is also capable of changing bits for situations requiring a different collection method. After collecting the sample, the drill stores the sample in a hermetically sealed container for future analysis. Previous rovers used drills to collect regolith for scientific observation but were not able to keep the samples. Honeybee Robotics has also designed a vacuum, the PlanetVac, for collecting regolith that is intended to be attached to the legs of a lander [22].

The rotorcraft used for sample collection would be optimized for maximum payload carrying capabilities. A trade study was used to determine the best sample collection method for attachment to a rotorcraft. Weight and power requirements were the largest considerations. The other criteria are related to the quality of the sample obtained. Five different mechanism types were evaluated in the trade study. The first is a regolith scoop attached to the bottom of the vehicle, operating similarly to a construction backhoe. The second mechanism is a regolith drill collecting samples by bringing the regolith up the drill's helix as it breaks up the surface rock. The coring drill is similar to the Mars 2020 percussive drill already designed but does not utilize percussion. The vacuum option is an adaptation of the PlanetVac designed by Honeybee Robotics, except it is modified to be transported by a rotorcraft instead of being affixed to a lander's leg. 


\begin{tabular}{|c|c|c|c|c|c|c|c|}
\hline Criteria & Weight & Scale & & & & & \\
\hline Weight & $30 \%$ & $\begin{array}{l}\text { 3:Least Heavy } \\
\text { 1:Most Heavy }\end{array}$ & 3 & 2 & 2 & 1 & 2 \\
\hline Sample Quality & $10 \%$ & $\begin{array}{l}\text { 3:Best Quality } \\
\text { 1:Worst Quality }\end{array}$ & 1 & 1 & 2 & 3 & 1 \\
\hline Repeatibility & $10 \%$ & $\begin{array}{l}\text { 3:Most Repeatable } \\
\text { 1:Least Repeatable }\end{array}$ & 1 & 2 & 3 & 3 & 1 \\
\hline Sample Variety & $10 \%$ & $\begin{array}{l}\text { 3:Most Variety } \\
\text { 1:Least Variety }\end{array}$ & 1 & 1 & 2 & 3 & 1 \\
\hline Sample Control & $10 \%$ & $\begin{array}{l}\text { 3:Most Control } \\
\text { 1:Least Control }\end{array}$ & 1 & 2.5 & 3 & 3 & 3 \\
\hline Power Required & $30 \%$ & $\begin{array}{l}\text { 3:Least Power } \\
\text { 1:Most Power }\end{array}$ & 3 & 2 & 2 & 1 & 1.5 \\
\hline Weighted Totals & $100 \%$ & 3 & 2.2 & 1.85 & 2.2 & 1.8 & 1.65 \\
\hline
\end{tabular}

Figure 9: Rock Sample Collection Trade Study Results

The results of the trade study, as displayed in Figure 9, show the regolith scoop and the coring drill both scoring the highest. While the regolith scoop's lightweight design and low power requirements gave it high marks overall, the sample quality, variety, and control of the coring drill makes it a viable option as well. The lack of percussion does eliminate the ability to drill very hard rocks and decreases the sample quality overall, but the samples would still be useful for research and scientific study. Collecting regolith carries risk as the rotors could disturb the regolith, reducing the sample size or blowing it away entirely. Another issue with regolith is determining a sample's actual origin. Martian winds could sweep regolith around the surface, making it unclear how to determine the regolith's original location. The amount of regolith disturbance by the vehicle's rotors is unknown, but the potential effects cannot be ignored. Therefore, the coring drill was chosen as the preferred method of sample collection because of its versatility, sample value, and relative low risk. If the weight constraints allow for a four kilogram drill, the percussive drill, with its better and more versatile samples, would be preferred. 


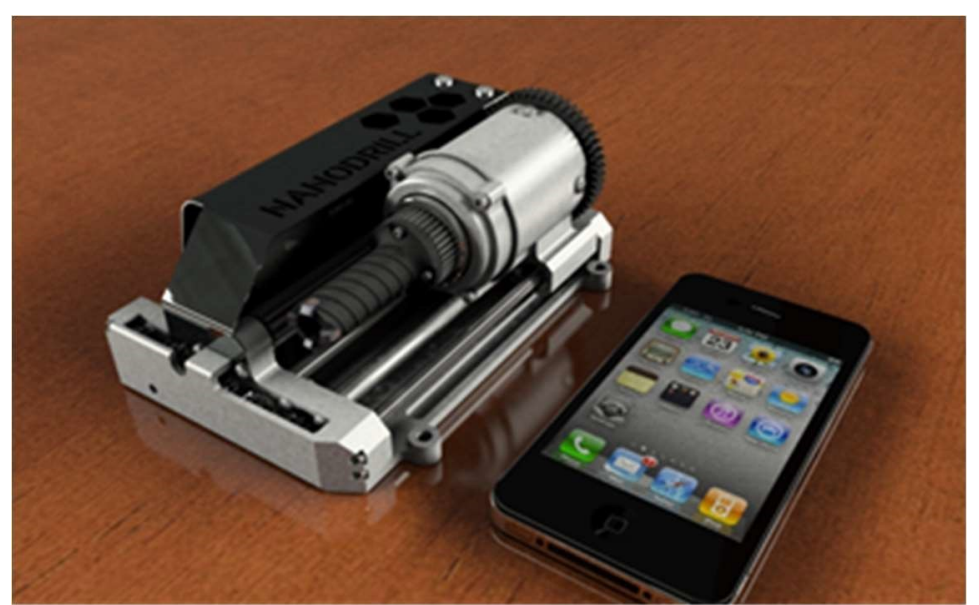

Figure 10: Nano Drill

Honeybee Robotics has designed a plethora of other drills for Mars besides the one used for the Mars 2020 mission. One drill, the Nano Drill [F10], was designed for use on the Axel robot for steep slope exploration. The Axel robot has yet to be used for extraterrestrial exploration, but the design constraints led to the development of a one kilogram percussive coring drill less than 6 inches long [23]. The existence of a more lightweight drill than the ROPEC makes the use of a percussive drill carried by a rotorcraft more plausible.

Currently all sample collection devices are evaluated as if they were mounted to collect the samples directly below a landed rotorcraft. Possible future improvements include the ability to actuate the sample collection mechanism so samples can be collected from different angles. For example, if a vehicle was able to collect samples from a canyon wall recently exposed by a rockslide, the sample could possibly come from a layer of the Martian crust currently inaccessible.

\subsubsection{Atmospheric Sample Collection}

Our current knowledge of the Martian Atmosphere is from orbital measurements, and while the scientific community has gained ample knowledge from these orbiters, there are inherent limitations associated. An in situ study would provide a higher resolution profile of the atmosphere in specific locations and assist in quantifying the carbon dioxide, water, and dust cycles.

\subsubsection{Science}

As mentioned in the Decadal survey's discovery missions [1], an atmospheric sample collection and return mission would be important in characterizing the Martian atmosphere. Understanding the present climate of Mars is a necessary first step in determining recent past and ancient Martian climates. Current satellite data is not sufficient to describe the processes controlling the present distributions of dust, water, and carbon dioxide in the lower atmosphere, a highly ranked objective 
for climate study. Direct, in situ measurements would make this possible and would provide calibration and validation for orbiter data and weather models [10].

Because of the satellites' orbits, measurements are limited, specifically over the poles, so there is insufficient atmospheric data gathered for the polar atmosphere. A rotorcraft would not have the same limitations and could take polar atmospheric measurements. Since they are constantly moving in their orbits, orbiters are generally limited in local time coverage and are not measuring diurnal variations in an area [10]. A rotorcraft has fewer limitations to the time it can spend in an area measuring day-to-day variations. Every area in the lower Martian atmosphere could have a vertical atmospheric profile created of higher resolution than satellites can provide, taken over ranges and altitudes not attainable by rovers.

\subsubsection{Mission Statement and CONOPS}

The Atmospheric Sample Collection mission shall provide in situ atmospheric sample collection to be later studied on Earth. The mission will provide a high-resolution vertical profile of Mars in multiple locations and provide diurnal observations that satellites cannot provide.

The Atmospheric Sample Collection system requires a lander and rotorcraft. The rotorcraft takes off vertically from the surface of Mars and begins its flight to the area of interest. When in place, the atmospheric sample is collected. If multiple samples can be taken, the rotorcraft will move to the next sample collection location. Once the desired samples are collected, the rotorcraft returns to the lander. The lander caches the rotorcraft's collected sample(s) and restocks the rotorcraft with empty collection devices. The rotorcraft charges and receives information for its next mission. 


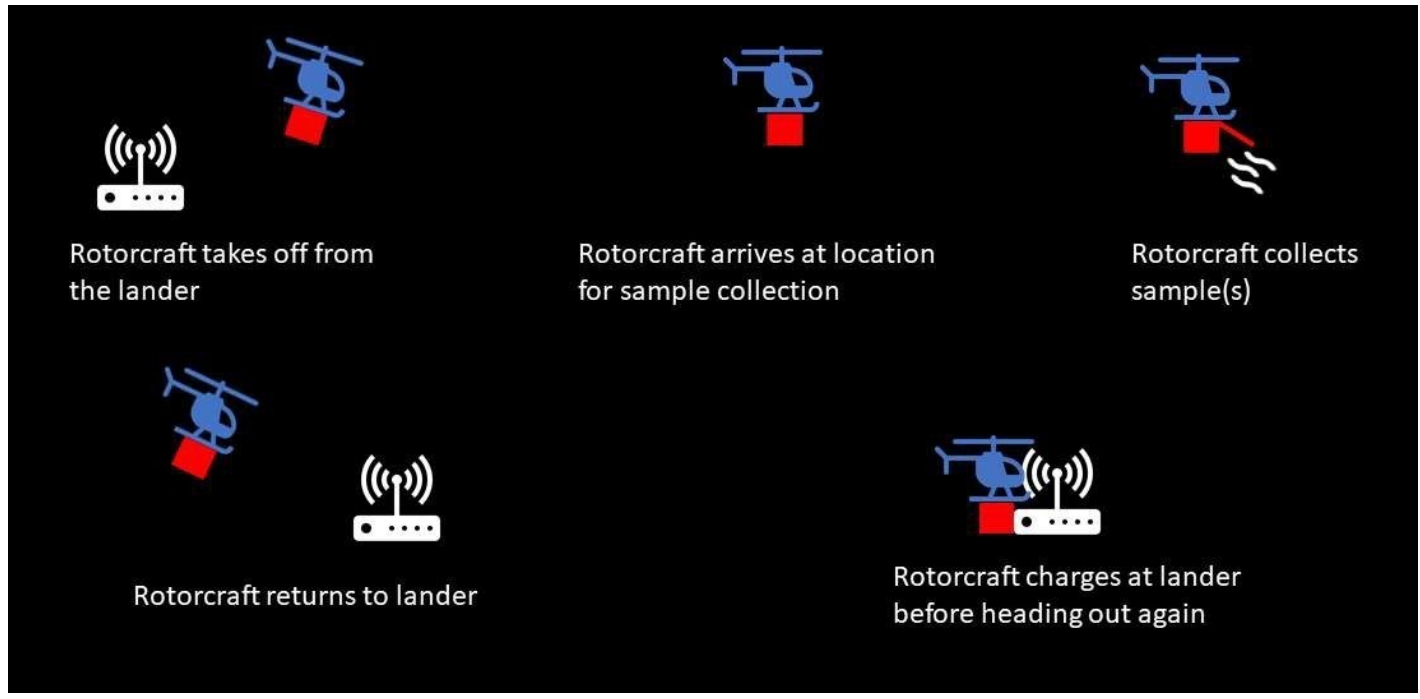

Figure 11: Atmospheric Sample Collection-CONOPS graphic

\subsubsection{Possible Challenges}

As with all systems on a Martian aircraft, the atmospheric sample collection device must be as light as possible. There are numerous methods to collect air samples, many involving fans or pumps to draw the atmospheric gases in, but these systems are typically heavy. In order to reduce weight in the design, a simple collection method should be used. A pre-evacuated canister with an actuated valve could be used as a whole air sampling component (WASC) [24]. Each canister would be single use, so enough canisters to complete the goals of the mission would need to be sent to Mars with the rotorcraft. The aircraft would also need to cache the samples for an Earth return mission, similar to the sample return mission for Mars 2020 [25]. If weight allows, the rotorcraft could also carry instruments to measure temperature, pressure, winds, radiation, magnetic field strength, and other characteristics of the lower atmosphere. This allows the rotorcraft to provide information about the conditions when the sample was collected, as well as continue to make scientific measurements after the sample collection is completed. 


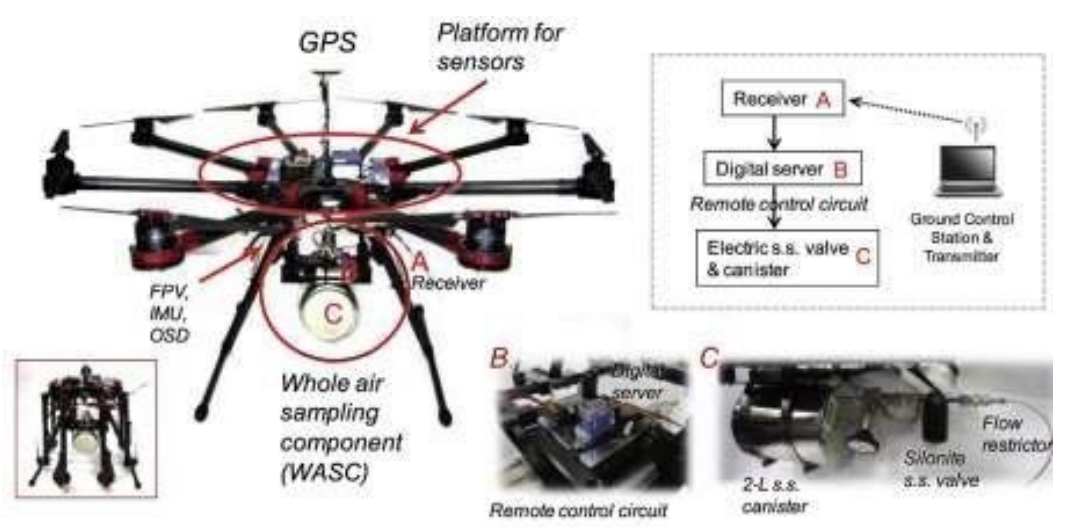

Figure 12: Existing WASC

A WASC integrated into a multicopter was developed at the Research Center for Environmental Changes in Taiwan in 2015. It was designed to take samples over an exhaust shaft of a roadway tunnel. Those samples were then analyzed in a laboratory for organic compounds. Superior sample

integrity and preservation conditions were reported when using the evacuated canister method.

\subsubsection{Polar Deposit Collection}

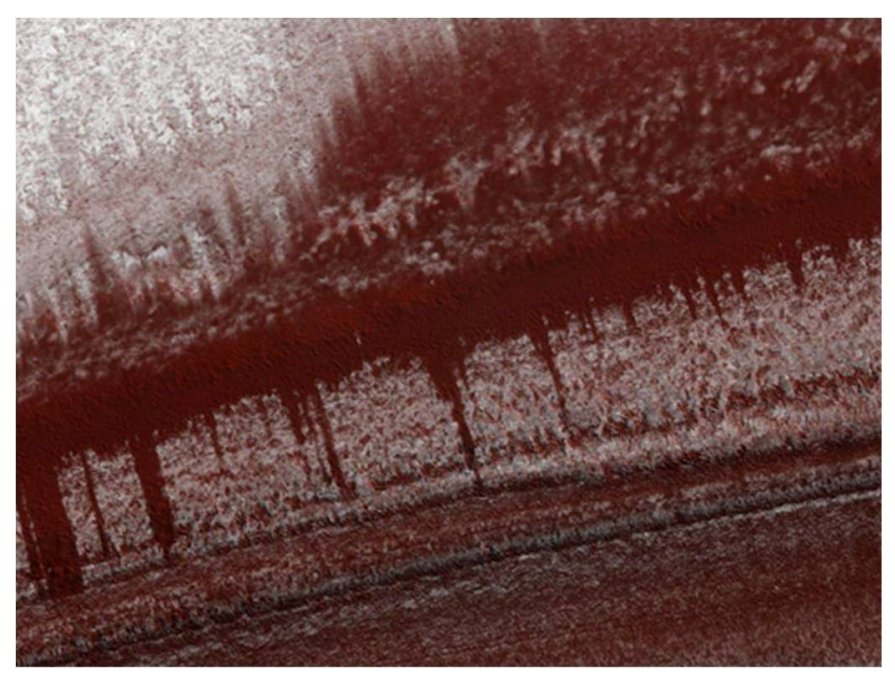

Figure 13: Mars Polar Layered Deposits
The poles of Mars are largely unexplored, and sending a vehicle there is important for furthering research into the planet's past climate. The poles consist of four layers: a seasonal layer of frozen carbon dioxide forms and sublimates with the seasons, a residual cap made of water ice that remains constant year-round, layered deposits holding trapped dust mixed with water ice, and a bottom comprised of dust and sand held together by water ice [26]. Layered

deposits hold the recent history of Mars's climate and are affected by the obliquity of Mars, climatic procession, and eccentric variation [27]. These layers are exposed in troughs or scarps in the ice [28]. This mission aims to research these layers and aid in learning more about past Martian climate.

\subsubsection{Science}

The science goal accomplished through this mission is to characterize the past climate of Mars. By analyzing dust samples trapped within the layered deposits, scientists can begin to piece together a 
timeline of the climate and characterize what Mars was like in the past as the obliquity changed. This mission can be best performed by a rotorcraft because they are able to vary their altitude and access different parts of the layered deposits, taking samples representing different periods in Martian history.

The main location for the mission would be in and around the North Pole. While the South Pole also has layered deposits, the North Pole is the preferable target because during the winter there is roughly 50\% more buildup of snow at the South Pole [29]. This makes it less likely for the vehicle to survive the winter if it were stationed at the South Pole. The snow particles are larger in the North Pole (8-22 microns) than in the South Pole (4-13 microns) [29], limiting the risk of the snow particles spreading to electronics and causing damage. Finally, the North Pole is larger than the South Pole, meaning there is more area for the vehicle to explore and collect samples from. The North Pole helps to lower the risks associated with Martian polar exploration, making it the preferable choice over the South Pole.

Within the North Pole there are exposed sections allowing a vehicle to reach the layered deposits and drill horizontally into the deposits directly without the need to dig deep vertically. These scarps and troughs cut into the North Pole, exposing the layered deposits [28]. A possible location for study is the Chasma Boreale, a location deep in the North Pole where it is possible for layered deposits to be exposed [30]. By using these natural troughs in the ice, energy and time is saved when collecting samples because less digging is needed.

\subsubsection{Mission Statement and CONOPS}

The Polar Exploration program will collect samples of the layered deposits at the North Pole on Mars using an air vehicle to characterize the past climate on Mars and help understand the history of Mars's atmosphere. An air vehicle is necessary for sample collection because it is able to fly to different sections of the layered deposits inaccessible by ground vehicles and collect samples from different elevations. Scientists can compare the contents of the samples from different elevations and understand how the climate has changed over time.

There would be two vehicles: a rotorcraft for sample collection and a lander to analyze the sample and provide shelter for the rotorcraft. When a mission is initiated, the lander releases the rotorcraft so it can collect a sample from the layered deposits. The rotorcraft will collect a sample from the layered deposits via a drilling procedure. Once the sample is ready, the rotorcraft will return to the 
lander and deposit the sample. The lander will analyze the sample and transmit the results to earth as well as receive the next mission and transmit the information to the rotorcraft. The lander will use nuclear power to inductively charge the rotorcraft. The lander will provide shelter for the rotorcraft to help limit the damage from the cold on the batteries and protect the rotorcraft from the elements between missions.

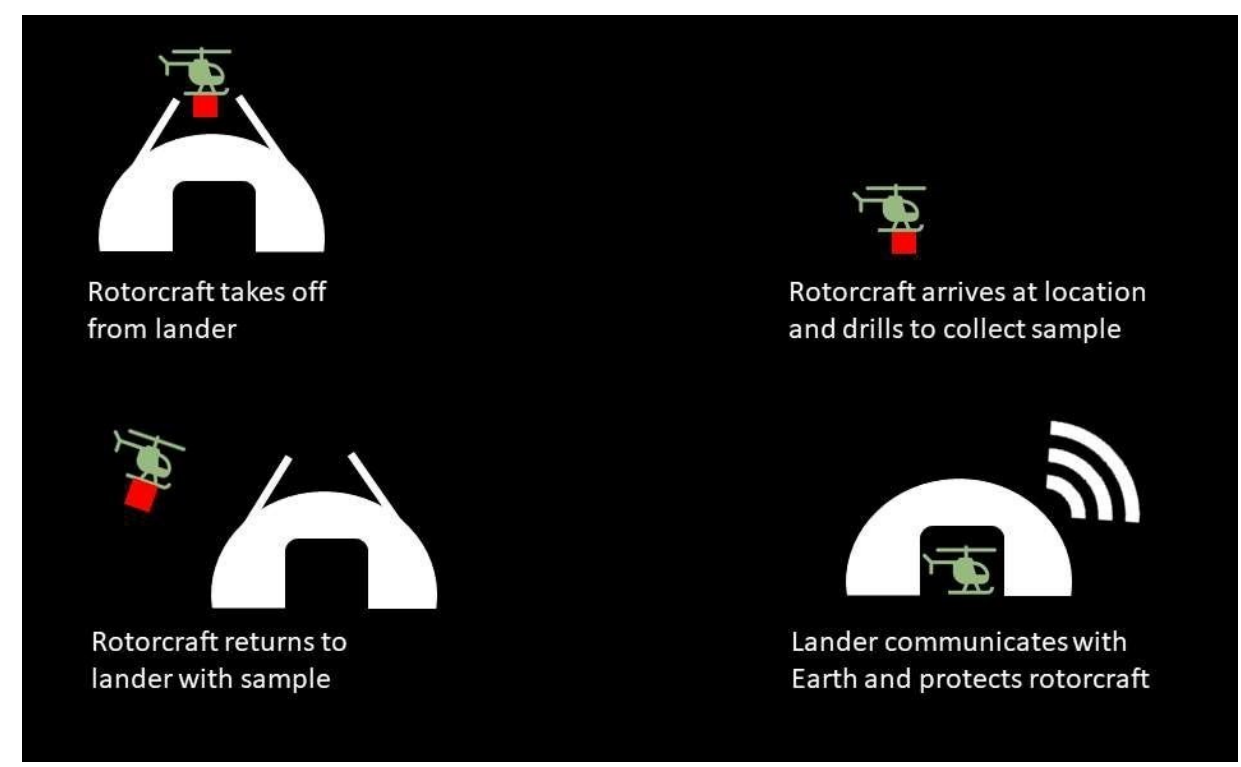

Figure 14: Polar Deposit Collection-CONOPS graphic

\subsubsection{Possible Challenges}

The rotorcraft will need to be able to collect usable samples from various elevations in the layered deposits and the area may not have a ledge for it to land on. This makes it important for the rotorcraft to be able to collect samples at an angle or from a vertical wall and not require a spot to land. The rotorcraft could press itself onto the wall with the drill attached and collect the sample or use a detachable drill. If the rotorcraft were to press itself against a wall, it would need to use an extensive amount of power to ensure the drill stayed pressed against the wall while collecting the sample. This could result in the rotorcraft running out of power and not making it back to the lander to recharge. If the rotorcraft were to use a detachable drill, it would be able to place the drill against the wall using a robotic arm and fly away to recharge before returning to collect the sample. The arm would need to be long enough, so the propellers do not contact the wall. As the arm extends, the center of gravity will change, and the rotorcraft will need to compensate. The detachable drilling unit would 
need to have its own separate battery because it would not be connected to the rotorcraft and, while this adds to the weight, it allows for the rotorcraft to save its battery for flying.

The detachable drill needs to be mounted onto the wall without slipping or falling even as the drill presses into the wall, applying a force and pushing the drilling unit away from the wall. There are a number of methods to achieve this. The drilling unit could quickly insert ice axes into the ice, wedging the axes and holding the drill firm against the ice. The problem is that the axes would need to swing rapidly, but springs cannot be used because in the extreme cold of the North Pole, the springs would become brittle and lose their elasticity. It would need to use a motor to swing the axes. Another method would be to insert a metal plate into the ice, creating a ledge for the drilling unit to be placed. This method may be unreliable if the plates are not able to

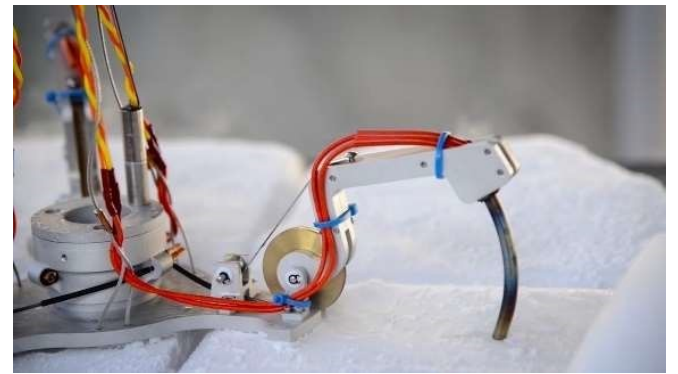

Figure 15: JPL Ice Claw dig deep enough into the ice to provide a stable surface for the drill. Additionally, this method does not necessarily push the drill towards the wall and, thus, does not hold the drill in place. A possible way for the drilling unit to form a grip is to melt the ice water and allow it to refreeze around feet or anchoring points attached to the drilling unit, fixing it into place. There is the possibility that the water ice just sublimates and there is not a way for the feet to get a grip. It might be possible to use a storage of liquid to be pushed out at the anchoring points and freeze quickly in the Martian air. Finally, a possible method is similar to Jet Propulsion Laboratory's "Ice Gripping Claw" [31] where four curved metal prongs are heated and melt into the ice and, once in position, cool off to create an area to grip onto the wall with. The main downside of this is that it takes time and energy for the prongs to melt into the ice and the rotorcraft would need to hover in place during this process. However, it takes less time than attempting to press the drone into the wall without the detachable drilling unit into the ice. Finally, the close proximity to ice walls increases the risk of a rotor strike. Shrouds can be used to protect the rotors, but there is a weight cost associated.

The lander will need to have a domed roof in order to protect the rotorcraft from the carbon dioxide snow during the winter. The lander will need to be equipped with instruments necessary to analyze 
the samples and have a nuclear power source to help supply energy to the rotorcraft, as there is not enough sunlight and too much carbon dioxide snow to rely on solar panels.

\subsection{Data Collection}

\subsubsection{Surface Mapping}

As stated previously, our knowledge of Mars has been informed by orbiting satellites and ground vehicles. Satellites have a limit on their attainable resolution and are restricted to overhead angles. Ground vehicles are limited by the terrain they can travel on, the distance from a landing site, and ground based angles. Equipped with imaging equipment, radar, LIDAR, or any other mapping sensor, rotorcraft have the ability to travel to places rovers cannot and gather in situ data and images at angles and resolutions rovers and satellites cannot achieve.

\subsubsection{Science}

An aerial mapping mission would fulfill multiple science goals and further understanding of the red planet. A rotorcraft has the ability to fly into canyons with walls too steep for rover traversal. Imaging of the layered deposits in the cliffs and walls of canyons will provide valuable insight into the history of Martian geology. It could aid current or future sample collection missions, creating a detailed map of an area of interest and pinpointing the optimal sample collection locations.

Rotorcraft would provide a new vantage point for mapping the canyon walls of Valles Marineris. For more detailed information on Valles Marineris, see section 3.2.1.1 page 16.

\subsubsection{Mission Statement and CONOPS}

The aerial mapping mission shall utilize air vehicles to provide high resolution in situ aerial surveys unobtainable by ground vehicles or satellites.

The mission will require one mapping rotorcraft that operates independently, not relying on a lander or rover. Once transported to the surface in an aeroshell, the rotorcraft will be able to begin its operations. It must perform a vertical takeoff from the Martian surface. A preplanned flight pattern will be flown autonomously, and data will be collected for the duration of the flight and transmitted directly to an orbiting satellite. Once the battery level has reached its lower flight limit, the craft will use its camera to find a landing zone and land autonomously. After landing, the rotorcraft charges via solar panels and receives data from Earth to determine its flight path. 
Since the rotorcraft will be self-sufficient, it will not be limited in range by any ground based technology, and its mission will continue across the surface for as far and as long as the craft is capable of traveling.

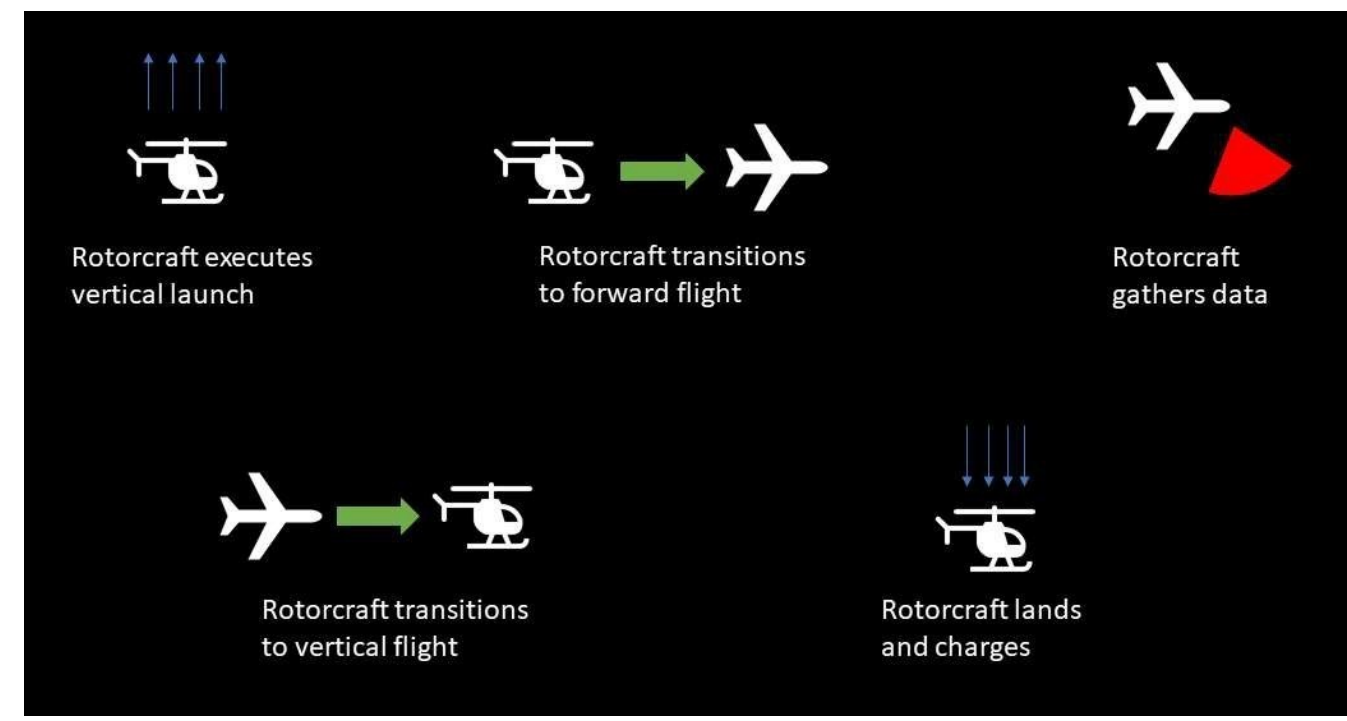

Figure 16: Surface Mapping-CONOPS graphic

\subsubsection{Possible Challenges}

This rotorcraft will be most useful if it has high flight speed and long flight time, enabling it to cover as much area as possible, while still able to hover and perform VTOL operations. These desired qualities favor a tiltrotor design. The primary difficulty of a tiltrotor design is in the transition between hover and cruise and the potential use of a wing to aid in lift.

Wing use on Mars poses significant challenges and will require extensive analysis and testing to determine if implementation is possible. To compare the flight differences between Earth and Mars, consider a wing with dimensions of two meters by 0.5 meters traveling at twenty-five meters per second. On Mars the wing is flying with a low Reynolds number of around 18,000 whereas Earth conditions produce a Reynolds number of 850,000. Using Martian air density and dynamic viscosity [32], airfoil data from a low Reynolds number airfoil [33], and accounting for gravitational differences, it was calculated that the wing on Mars would be able to lift around one kg while the wing on Earth would lift almost $43 \mathrm{~kg}$. While the lift produced would be drastically lower, reducing the required lift from the rotors by one $\mathrm{kg}$ would still be beneficial, assuming the weight difference between a wing solar panel and an equivalent standard solar panel is minimal. Perhaps a tiltrotor 
aircraft could be designed to operate at an angle between 0 and 90 degrees, somewhere between traditional hover and cruise. It would not rely completely on a wing for lift, but would greatly increase the thrust vector in the forward direction. Further analysis is required to determine possible rotor angles and the effects on flight characteristics and maneuverability.

\subsubsection{Cavern Exploration}

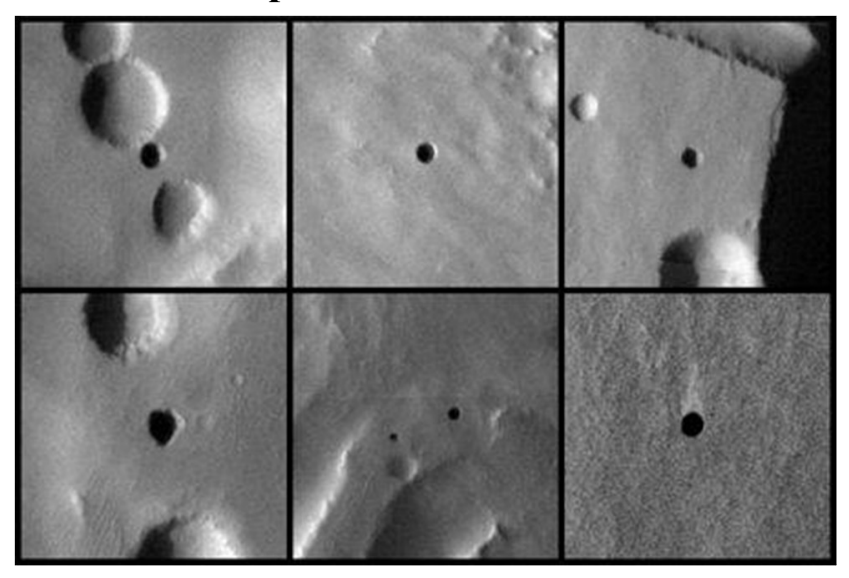

Figure 17: Mars Caves

Satellites and high-powered cameras like THEMIS have picked up images of holes in the Martian surface, alluding to caves and subsurface tunnels, but there is no way to enter or scan these features with the technology currently available on Mars. Satellites cannot penetrate the crust and can only view so much of the interiors through the entrance. Present rover technology is not agile enough to safely descend into caverns and is incapable of extraction. The current atmospheric and geographic conditions of the Martian subsurface are unknown. The Cavern Exploration mission is designed to perform the initial survey so future missions can perform further explorations of the subsurface.

\subsubsection{Science}

This mission helps advance multiple scientific goals and sets up other missions to accomplish the full range of scientific goals. Since these caves have been protected from outer environmental changes, there is a higher potential for biomarkers and organic life, both imperative to furthering the life goal. The geographical evolution of Mars could also be preserved beneath the surface, advancing the geology goal. Cavern exploration is a key component of the human exploration mission because initial studies predict that subsurface caves may be more viable than the surface for permanent structures. The subsurface heat difference may provide an environment that can hold a sustainable source of liquid water, which would be valuable for enabling a long-term human presence on Mars [1]. 
As described before, Arsia Mons, due to its likelihood of containing caves, would present an ideal target for cavern exploration. These caves have the potential of harboring biosignatures and other scientifically intriguing targets due to its protection from the surface climate. A sustainable source of water ice paired with protection from the Martian atmosphere makes these caves an optimal potential landing site for human missions.

\subsubsection{Mission Statement and CONOPS}

The Cavern Exploration mission shall scout out designated caverns to prepare future vehicles for traversal.

This mission will be accomplished by recording environmental readings near or within cavern openings, creating a profile of physical requirements for rovers, and enabling detailed mapping of exploration zones.

The Cavern Exploration mission will be one of three rotorcraft configurations. Possible rotorcraft configurations include a single rotorcraft, two or three similarly designed rotorcrafts, or a swarm of small drones transported on a larger drone or rover. The chosen arrangement, known as the exploration team, will establish contact with the lander. Once initial contact has been established, the lander will receive the coordinates for the exploration team to travel towards autonomously and upload them to the team. Previously collected data on the cave, either from satellites or previous missions, will be used to create a designated safe zone, an area determined to be as close to a yet unsearched area as possible while still offering conditions that will not pose any risks to the rotorcraft. The team will then depart and head towards its location, stopping to recharge or wait on the ground for a storm to pass as necessary. Once the team arrives, the rotorcraft will head to the designated safe zone at the mouth of the cave, disconnecting from a transportation vehicle if necessary. Imaging and atmospheric scans will be taken in the zone and recorded onto the rotorcraft's memory until the memory is full or all reachable information has been recorded. If the exploration team layout is a drone swarm, they may periodically return to the transport vehicle to upload information and recharge during the scanning process. Once one of the limitations is reached, they will reattach themselves to the vehicle to prepare for the return trip. The exploration team will return to the lander, recharging and preparing for dust storms as necessary. Once the team has returned to the lander, it will attach itself and upload collected information to the lander to be sent back to Earth. While waiting for new orders to be sent, the exploration team will spend time performing basic 
maintenance tasks (i.e. running software diagnosis programs, recharging, and cleaning dust from the lander). A new task, based on the information collected from the previous task, will be sent back to the lander and uploaded to the exploration team. This information will be used to send the exploration team back to an expanded safe zone or will direct the team towards a different destination. This process will continue with each site until it has been determined that no further exploration of the cave is necessary, a cave has been designated too dangerous for exploration to continue at that time, or enough information has been collected so a vehicle designed to explore that subsurface area can continue more thorough research and sample collection.

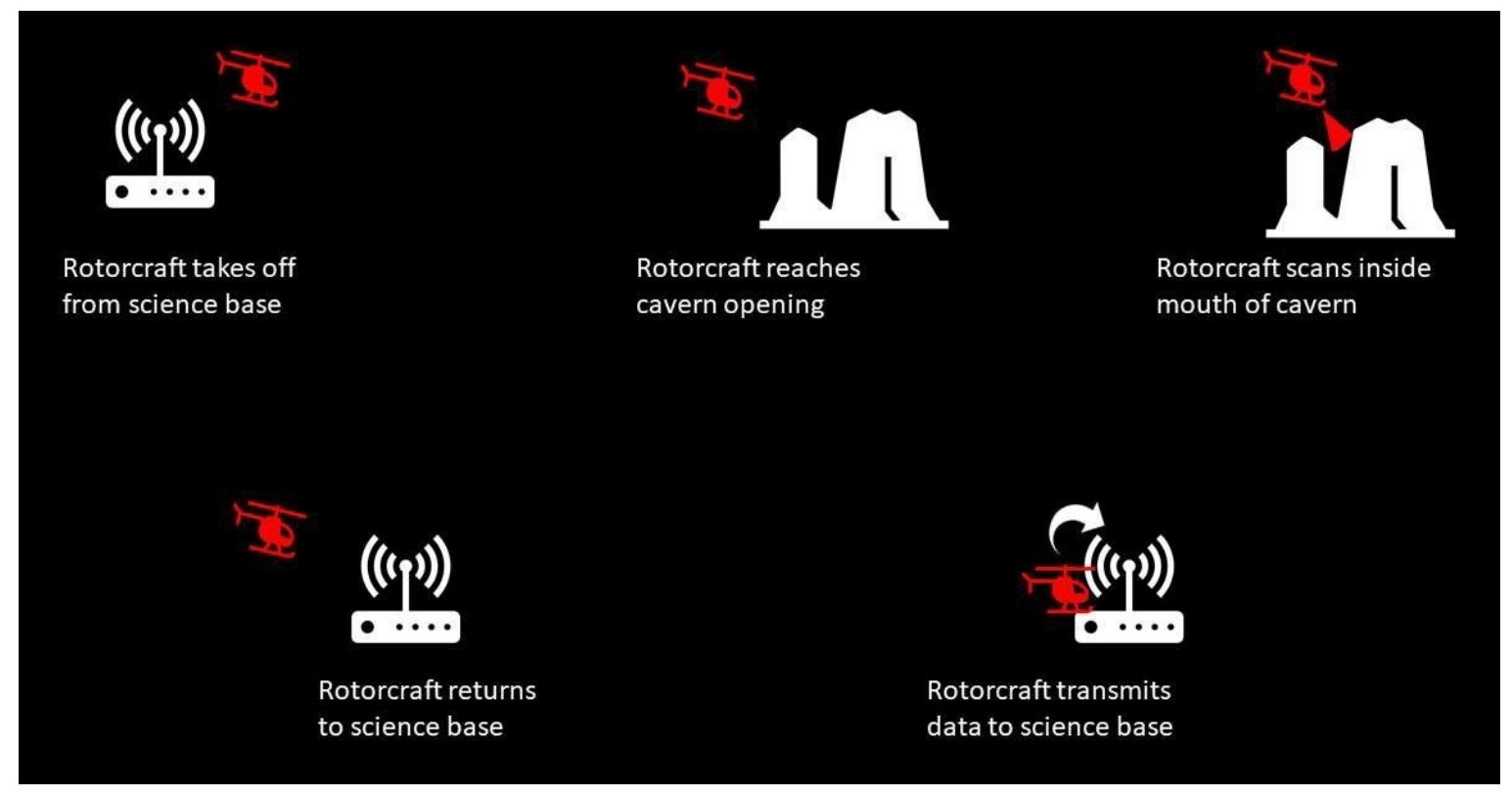

Figure 18: Cavern Exploration-CONOPS graphic

\subsubsection{Possible Challenges}

Cavern exploration poses a number of risks and challenges impacting the rotorcraft's design. The primary challenge is the risk of connection interference between any above-ground vehicles and below-ground rotorcraft. If multiple vehicles are used, a local connection must be maintained to avoid collection redundancy and collisions. Since further trips will require deeper descending into the cave, signals are at risk of distortion or complete severance. Because the atmosphere subsurface is unknown, there is also a chance there could be chemical, electrical, or radioactive factors that can cause sensor and connection malfunctions. There are also considerations for the different possible rotorcraft arrangements. The single and multi-craft arrangements require the rotorcraft(s) to be equipped with individual sensors, data banks, and charging capabilities, something that will increase 
the size of the rotorcrafts and limit the crevices they are able to explore. While the multi-drone system would be able to divide the weight needed and reduce the data bank size on-board, it has not been determined if the size decrease is significant enough to make it worthwhile. It is yet to be determined if the limitation imposed by the space available in the aeroshell's interior will make multiple drones a non-viable option. This is especially true in the case of the swarm layout. Even without the extra hardware, the drones need to be large enough to carry the necessary hardware and still be able to achieve significant amounts of lift. Even if sensors and flight hardware were designed to be small, the surface area needed on the propellers still needs to be significant in size because flying in Martian atmosphere doesn't generate the same percentage of lift as flying in Earth's atmosphere. This means smaller rotorcraft, ideal for in-depth data collection, may not be realistic with current engineering limitations and would limit what skylights and caverns a swarm would be able to explore. A flying transport vehicle would be ideal for speed, but may not be feasible since it would have to be larger than the drones it is transporting so it can fly not only itself but the attached swarm members as well. If the transport vehicle was a rover, it would need to cope with all the undesirable constraints on land-based vehicles (i.e. reduced speed, terrain limitations). Determining the proper layout for this mission requires optimizations and tests to be performed to decide which layout is the most efficient. Another issue is that regolith may be light enough to be disturbed by rotor movement. When a drone is high above the surface there is little risk of disruption, but since the rotorcraft is meant to descend, it could kick up debris and cause a Martian brown-out. As such, technological advancements will be required to find solutions to these current considerations.

\section{Vehicle Concept Designs}

\subsection{Design Considerations}

Most traditional multirotor aircraft use fixed rotors and variable RPM for control because of the simplicity and cost effectiveness of the system. In the thin Martian atmosphere, a large RPM change is required to increase the thrust, making RPM controlled motion less responsive.

Collective pitch used to control the thrust from each rotor can be an effective and viable form of control. If using collective pitch for control, all of the rotors will be spinning at the same RPM, allowing the possibility of using fewer motors and a drive system to spin the blades. However, 
collective control adds complexity and small moving parts and linkages to each rotor. Another option for control is thrust vectoring by individually tilting fixed pitch rotors, especially for a vehicle already utilizing tiltrotors.

The aircraft must be capable of fully autonomous operation. Any control signal from Earth would take too long to get to Mars to allow the vehicle to react to flight conditions or obstacles.

\subsection{Integrated Concept Vehicles}

Designs of possible Martian rotorcraft were created, taking into account the challenges and limitations imposed when flying on Mars. These designs are conceptual in nature and are meant to explore possible configurations and control systems that may be beneficial or required on Mars. The models have not been sized or optimized at this stage, besides the constraint of current aeroshell size limitations and basic tip speed considerations. The propellers are all currently dimensioned at 1 meter in diameter, similar to the Mars Helicopter's 1.2 meter diameter. In the cold temperatures of Mars, the electronics need to be contained and insulated. For these conceptual models, the electronics are modeled as an insulated box, similar to the Mars Helicopter.

\subsubsection{Long Range}

Current in situ Mars exploration is very limited in range. Rovers operate at low speeds, and Mars has many areas that are difficult or impossible for the rovers to traverse on the ground. Curiosity has traveled about 13 miles in 2459 sols, or just under 30 feet per sol. While it has made many important discoveries, its area of exploration is very small on a planetary scale. The use of rotorcraft eliminates many of the speed and range problems, and though it introduces other challenges, it can still greatly increase the area of in situ exploration on Mars. A long-range rotorcraft has useful application in data collection or collecting samples over a large distance.

\subsubsection{Tiltrotor}

In order to extend the range and endurance of a rotorcraft, wings are often added to produce lift so the rotors are not required to provide all of the lift and thrust forces, improving the longevity of the batteries and allowing the aircraft to operate at greater speeds. Due to the low air density of Mars, wings are not as effective as they are on Earth. However, one method of charging electric rotorcraft is through the use of a solar panel, and it could be beneficial to utilize that solar panel as a wing, making a tiltrotor aircraft with a solar panel wing a candidate for long range flight on Mars. A control system based on the thrust vectoring of the rotors allows for the reliable simplicity of a fixed pitch 
rotor, and a motor tilting mechanism can be more robust than pitch control linkages. In addition to the lift from the wing adding range, the large solar panel wing can theoretically charge the battery during flight and further increase the flight time. The wing can also have tilting capabilities in order to charge more efficiently when on the ground by orienting the panel towards the sun.

\subsection{Quadcopter Tiltrotor}

This concept is an $\mathrm{H}$-frame tiltrotor with individually tilting fixed pitch rotors that tilt on the lateral axis. It has a large solar panel wing in the center over the landing legs and insulated electronics box.

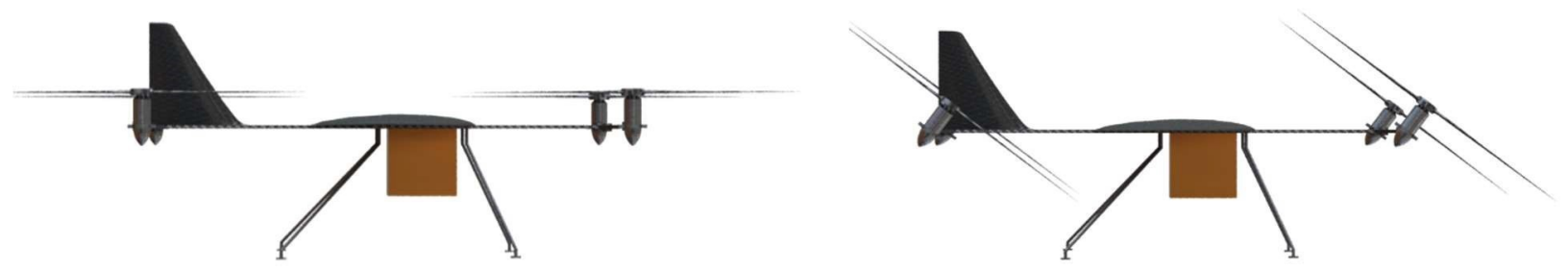

Figure 19: Quadcopter Tiltrotor in hover and forward flight transition

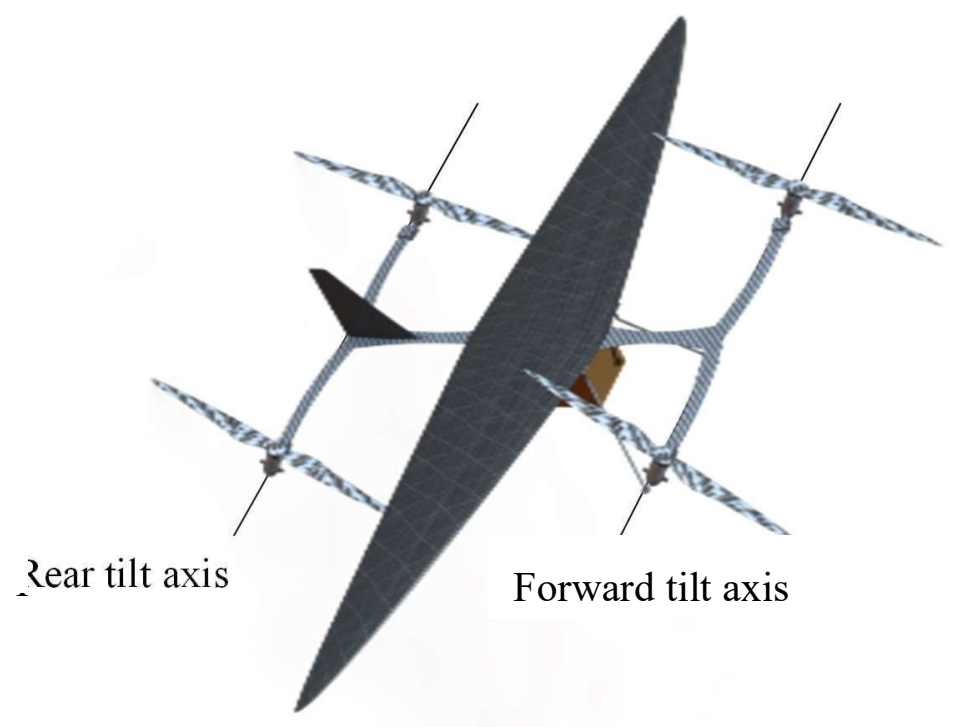

Figure 20: Quadcopter Tiltrotor tilt axes

\subsection{Octocopter Tiltrotor}

The same $\mathrm{H}$-frame concept can be applied to an octocopter by vertically stacking another motor and rotor under each existing set. Adding extra motors increases available thrust, a very valuable quality 
on Mars, but decreases battery life and adds weight and complexity. While still difficult due to the number of rotors at different angles, the control system of this rotorcraft is partially simplified compared to the quadrotor design. Since all rotors are in pairs, the torques cancel, and no additional adjustments need to be made to account for a changing torque vector.

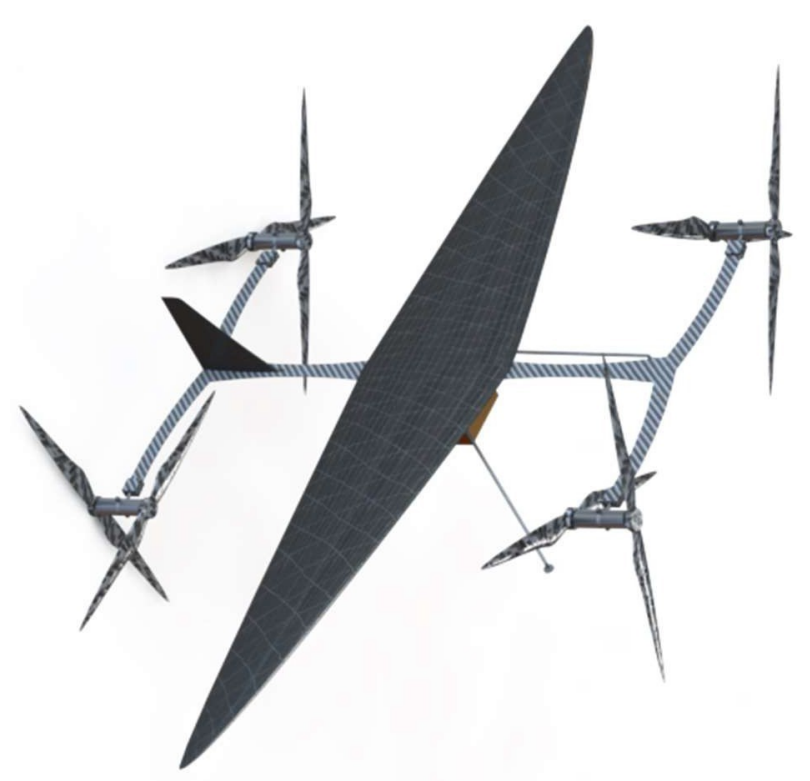

Figure 21: Octocopter Tiltrotor

\subsection{Dual Tilt Hexacopter}

Instead of using a wing for lift and tilting all the rotors, many configurations can be designed with some rotors used for lift and some (tilting or rigid) used for forward motion. One such configuration is a hexacopter with four collective pitch rotors and two tilting rotors. All six rotors can be used for vertical lift or two of the rotors can be tilted forward for faster, level forward flight. Further analysis must be performed to determine flight characteristics in transition and quantify interference in forward flight. 


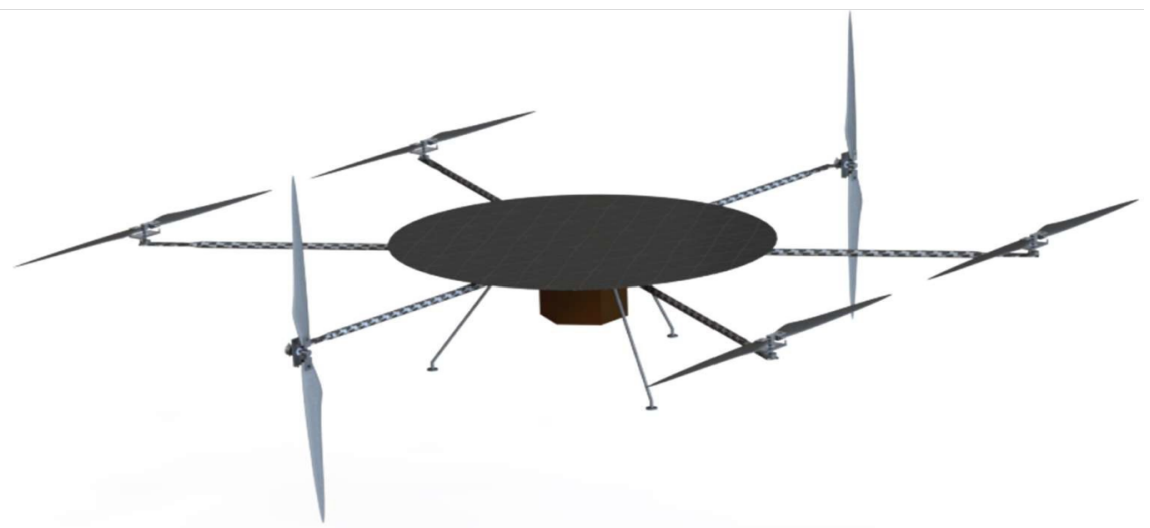

Figure 22: Dual Tilt Hexacopter

\subsubsection{Heavy Lift}

When long range or speed is not a high priority for the mission, increasing lift generation to carry larger payloads is an area of high interest for Martian flight. On Earth, more lift can be produced by building a larger aircraft with larger rotors, but this is primarily done for internal combustion or turbine power systems. As with Earth, the size of the electric aircraft is limited by battery weight in its electric propulsion system. Additionally, Mars aircraft are limited by the dimensions of the aeroshell transporting them. Multirotor systems offer large amounts of lift in battery powered systems. Multirotor configurations of at least 6 rotors adds redundancy, providing protection for the mission since the craft can still complete its mission even if one of the motors goes out or the rotor is damaged, an important consideration for a vehicle that cannot be serviced.

\subsubsection{Overlapping Blades}

In the Martian atmosphere, ratio of rotor size to aircraft size is greater than on earth because of the effect on lift from a thinner atmosphere. In order to conserve space, each rotor is placed at one of two alternating heights, allowing the rotors to overlap each other. The rotors all spin at a constant RPM and have collective pitch to change their thrust output. The overlapping blades allow for more thrust in a more compact design, which is important for the transportation to Mars. 


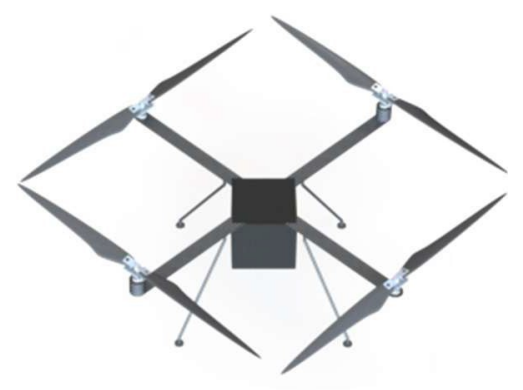

Figure 23: Overlapping Quadcopter

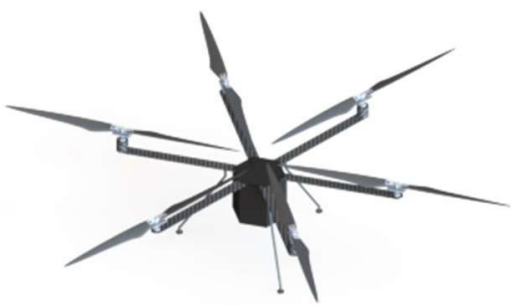

Figure 24: Overlapping Hexacopter

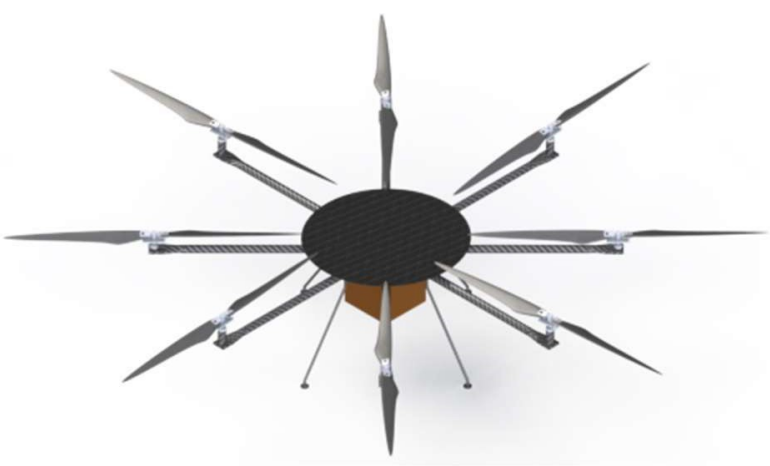

Figure 25: Overlapping Octocopter

The overlapping blade concept can be taken a step further, doubling the rotors by stacking them vertically on a similar frame. This is the approach taken by the coaxial configuration of the Mars Helicopter, and it can be similarly applied to a multicopter for additional redundancy and anti- torque benefits.

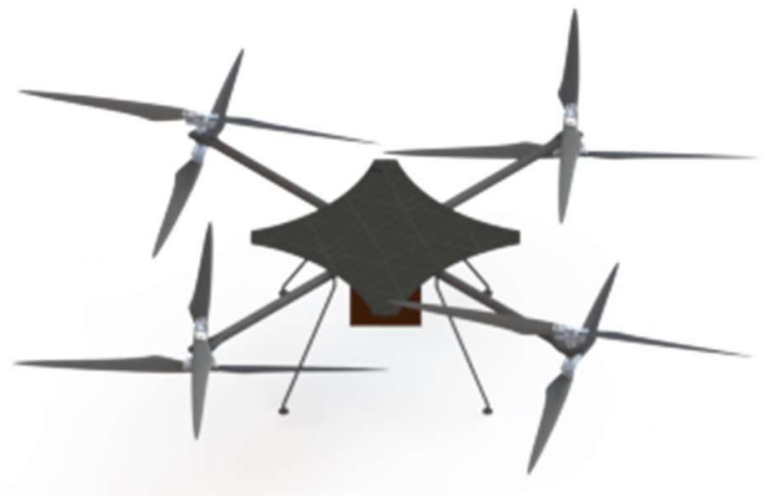

Figure 27: Stacked Octocopter

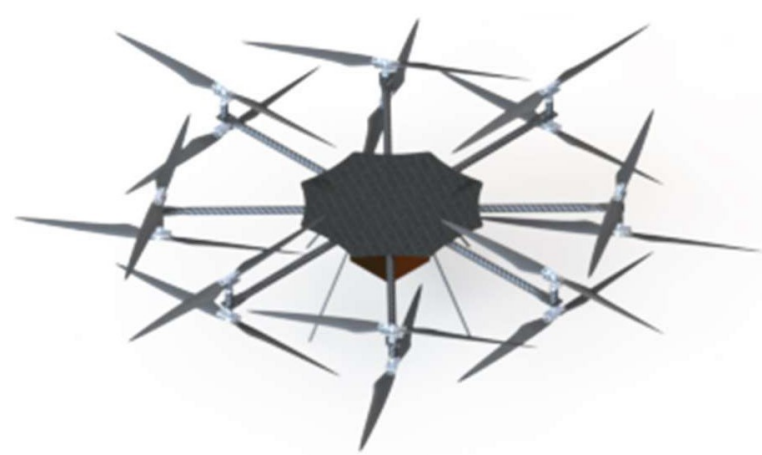

Figure 26: Stacked Hexadecacopter 


\subsection{Component Designs}

\subsubsection{Folding Propellers}

In an effort to conserve space in the transportation of the rotorcraft to Mars, the rotors can be folded to drastically reduce the vehicle's footprint. The centrifugal force caused by the spinning of the rotors will keep the rotors in the correct position during flight, so this design will minimally impact the actual performance of the craft.

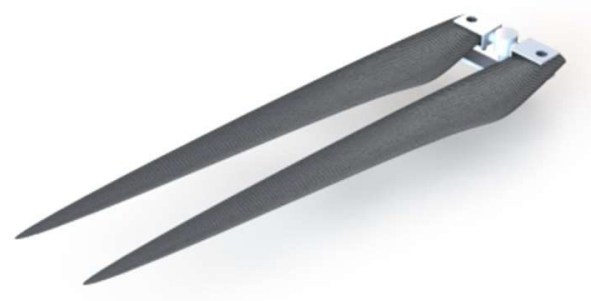

Figure 28: Folding Rotor

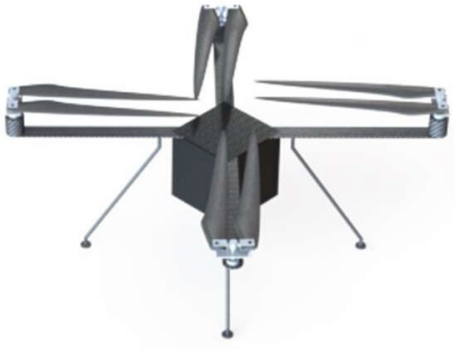

Figure 29: Folding Quadcopter

\subsubsection{Folding Solar Panels}

In an overlapped quadrotor design, almost the entire area above the aircraft is under the rotor disk. In order to maintain a large enough solar panel area to charge without interfering with the thrust from the rotors, the solar panels can be designed to be foldable. When in flight, the panels are folded down and stored, then once landed the panels unfold for increased surface area to decrease charging time.

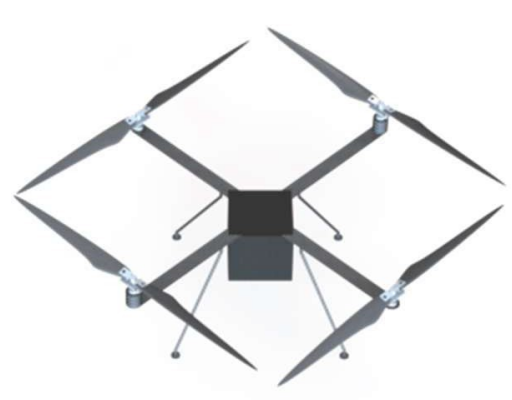

Figure 30: Flight Mode

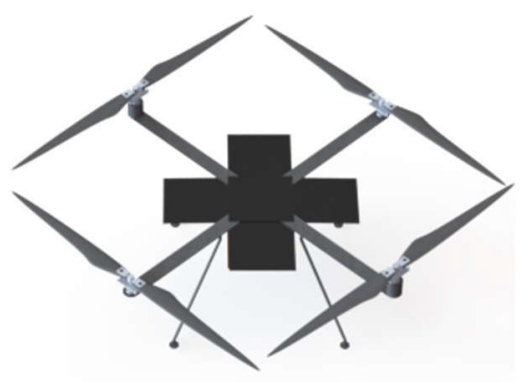

Figure 31: Charging Mode 


\subsubsection{Ice Claw}

A claw would be able to heat up the four metal prongs and melt them into the ice in order to get a grip on even a vertical ice wall. The hole in the center allows for a drill to be inserted through it and collect a sample. The claw would be attached to an arm connected to the drone. This would be a part of the detachable drilling unit mentioned in the Polar Exploration Mission. Since no heating power is required once the claw is attached to the wall, the power source for heating could be the main aircraft battery as long as the connection interface has power.

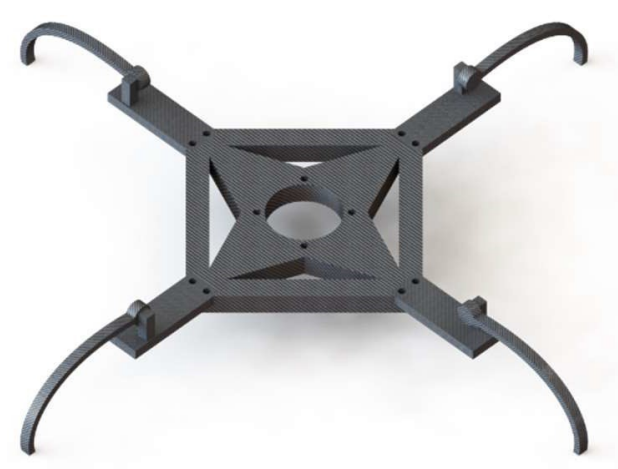

Figure 32: Ice Claw

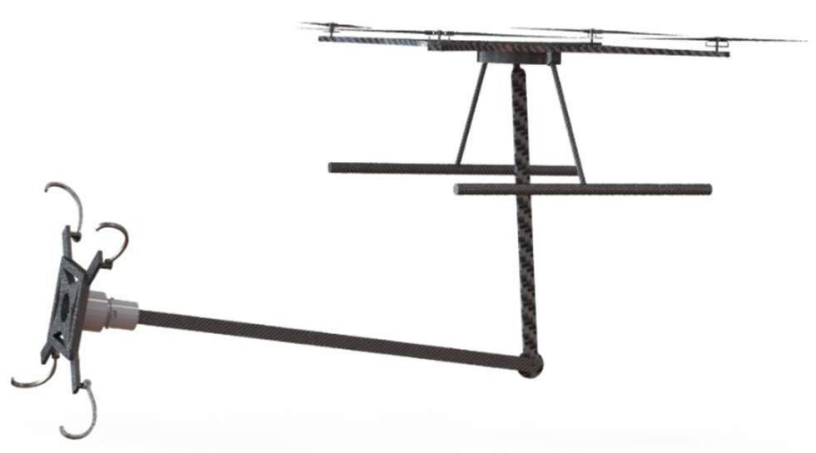

Figure 33: Ice Claw with Rotorcraft

\subsubsection{Tilting Solar Panel}

All aircraft with fixed solar panels will have the panels oriented horizontally to minimize drag during flight. When charging on the ground, it is most efficient to position the solar panel toward the sun, wherever it is in the sky. This can be achieved by placing the solar panel on a telescoping arm with a rotating actuated joint and adding complementing sensors so it can always direct itself towards the best charging direction. The telescoping arm adds an estimated 200 grams, so weight added must be compared to charging efficiency increase to determine viability of implementation. 


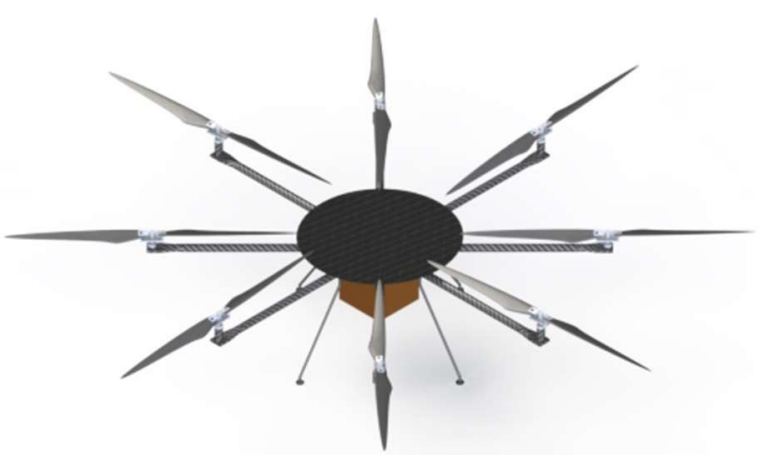

Figure 34: Tilting solar panel in flight mode

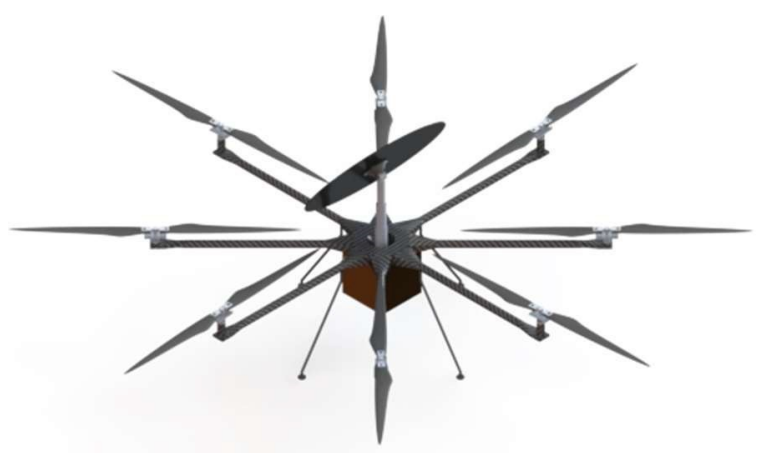

Figure 35: Tilting solar panel in charging mode

\subsubsection{Drill}

A potential drill model was designed using the drill previously created for the Mars 2020 mission, the Honeybee Robotics ROPEC drill as a reference. A breakoff mechanism was built into the drill bit itself in order to collect the core sample. After collecting the sample, the drill bit becomes the cap for the hermetically sealed sample container [21]. Sealing the sample immediately is important to keep the sample secure and protected from contaminants while the rotorcraft is transporting it back to base. For that reason, the sleeve is available on the vehicle so the sample can be sealed without having to travel back to base. Reloading the drill would have to be done by a robotic arm or other mechanism on the lander. The sample collection aspect of the drill would be powered by the rotorcraft. This design includes a pivot point requiring a servo motor, two lead screws requiring motors, and a drill motor as the power consuming elements. Figure 37 shows the drill mounted on the bottom of a stacked octocopter to display the size of the device in relation to a vehicle.

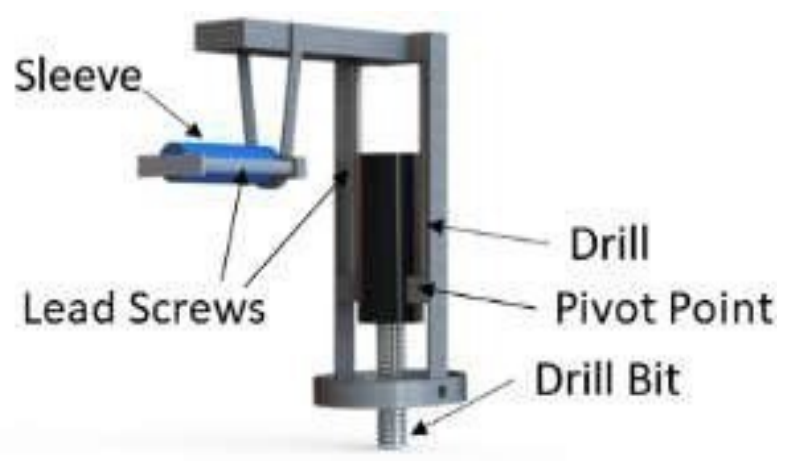

Figure 36: Coring drill concept design in drilling mode 


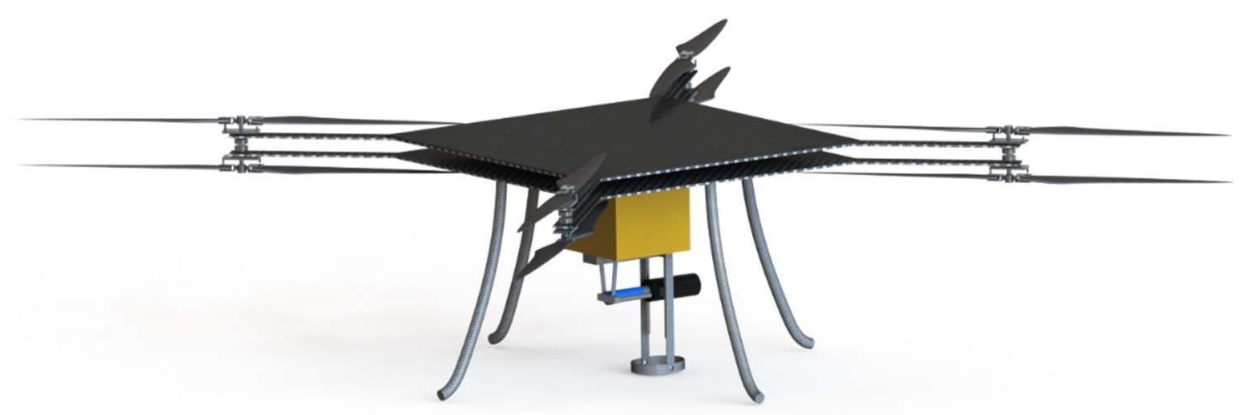

Figure 37: Drill mounted on stacked octocopter with drill in sample carrying position

\section{Conclusion}

The Mars 2020 Helicopter and its mission signals a shift in technology for extraterrestrial exploration. Some of the boundaries that faced previous Martian missions can be overcome by rotorcraft, opening up a new realm of discovery. Rotorcraft missions on Mars are an important component for expanding our knowledge of the past, present, and future of the planet's environment and may hold the key to unraveling mysteries involving Earth's transformations. Suggested missions focus on the categories of rover assistance, sample collection, and data recording to utilize this technology. These missions were designed with the MEPAG goals of life, climate, geology, and human exploration in mind [10]. Each mission aims to further the research being done in at least one of these four areas.

Martian flight is not without challenges. The environment presents engineering challenges not found on Earth, like reduced lift and gravitational changes. Even with the 2020 Mars Helicopter's success, achieving sustained flight in Mars's atmosphere continues to be a challenging endeavor. However, the scientific benefits make the technical challenges worth investigation and overcoming them can lead to a better understanding of our universe.

\section{Future Work}

This paper documents current interests in exploring Mars, describes potential future Mars missions for rotorcraft, and suggests possible rotorcraft concepts and configurations for use on Mars. To further this project, the scope will have to be narrowed and specific aspects will need to be investigated in detail. Missions will need to be analyzed to develop specific aircraft design requirements for each individual mission. Parameters for missions will need to be input into NDARC, a design optimization tool, to obtain sizing and design information for the rotorcraft. 
Conceptual design configurations will need to be run through CFD analysis to determine the effects of overlapped blades, tiltrotors in different flight configurations (especially with wings), solar panel interaction, etc. Control systems will need to be made for uncommon control types such as collective pitch multirotors and especially for unorthodox control types like individually tilting rotors, a system that requires accounting for the changing torque of each rotor as it moves [34]. The conceptual designs will need to be developed into detailed designs, and individual systems will need to be engineered (tiltrotor mechanisms, solar panels, folding components, airframe, etc.). The exact necessary sensors and instruments will need to be determined, and components will need to be specified and sourced. Prototypes need to be built and tested. One thing the Mars Helicopter will not demonstrate extensively is prolonged forward flight; therefore these rotorcraft will need numerous tests in a vacuum wind tunnel to determine forward flight characteristics. The culmination would be working with multiple NASA centers to design the total mission (from launch to flight mission completion on Mars), implementing it, and sending the rotorcraft to Mars.

\section{Acknowledgements}

We would like to thank the Alaska Space Grant, Missouri Space Grant, and Wisconsin Space Grant for their support of this project. Special thanks to Shannah Withrow for trusting us to think outside of the box for future Martian rotorcraft and for providing guidance as the project evolved. Additionally, thanks goes to Larry Young for guiding us to push the boundaries of what is currently possible. Thanks to Lainey Rodgers for her enthusiasm and assistance in exploring Mars through proposed landing sites. Another huge thank you goes to Bill Warmbrodt for his constant support, fearless leadership, and arguably endless knowledge of California history.

\section{Personal Contributions}

Michael Radotich was the team lead for the Mars Mission Design group. He focused on the flight considerations for rotorcraft on Mars and their implications for possible vehicle designs. He wrote the surface mapping and atmospheric sample collection missions in the paper, as well as the flight on Mars, future work, and vehicle concept design (minus the ice claw, folding propellers, and drill components) sections. He did preliminary analysis and calculations on wing lift in the Martian atmosphere. Time was spent researching proposed Mars aircraft, VTOL air vehicles (particularly tiltrotors), and current capabilities and limitations of current Martian orbiters and rovers. All of the full vehicle concepts in the report were conceived and modeled in SolidWorks by Michael. With 
Henry's assistance, he remodeled 7 of the vehicle concepts into 3D-printable scale models and printed them for Shannah's use in outreach.

Zarya deSouza worked in the Mars Mission Design group. She mainly focused on the locations and science opportunities made possible by using rotorcraft on Mars. She also created the CONOPS graphics for all of the missions. For the paper, she wrote the Rover Assistance and the Rock Sample Collection missions including the trade study for the sample collection device. She also contributed to other sections by providing location examples for the other missions. For the literature review, she worked on the section about landing site selection and some locations, specifically Valles Marineris and Arsia Mons. Using Solidworks, she modeled a potential air vehicle and other components including a folding propeller with collective control for packaging and a drill concept for the Rock Sample Collection mission. She contributed to writing and formatting the poster for the symposium at the end of the summer. She also assisted with editing the poster and paper through their many versions.

Sophie Gelhar worked on the Mars Mission Design project. She researched Martian caves and primarily focused on the section about the Cavern Exploration mission. She worked on the Literature Review part of the paper and summarized the Planetary Decadal Survey's research goals and studied the Mars chapter of the survey as well as the 2018 MEPAG document in- depth. She did research on previous technology and research goals for Mars prior to the writing of the paper. She also contributed to editing the paper during its multiple stages, also writing the paper's conclusion. She assisted in the wording and formatting of the Mars Mission Design poster.

Henry Gallagher worked in the Designing Mars Missions using Rotorcraft Technology group. He learned how to use SolidWorks, and used this to aid in the creation of concept vehicles and tools such as the ice claw found in the paper. He designed the claw based off the JPL Ice Claw design which is referenced in the paper, but made some changes to the shape and structure which he thought better suited the needs of the project. He used this software to edit and scale the models which were 3D Printed for the project. He researched Mars's Poles and wrote the Mars Polar Deposit section of the paper, and aided in the formatting of the paper. 


\section{References}

[1] Vision and voyages, Washington, D.C.: National Academies Press, 2011.

[2] Williams, D. (2019). Mars Fact Sheet. [online] Nssdc.gsfc.nasa.gov. Available at: https://nssdc.gsfc.nasa.gov/planetary/factsheet/marsfact.html [Accessed 29 Jul. 2019].

[3] Petculescu, A., and Lueptow, R., "Atmospheric acoustics of Titan, Mars, Venus, and Earth", Icarus, Vol. 186, No. 2, 2007, pp. 413-419, doi: 10.1016/j.icarus.2006.09.014

[4] "Mars Facts | All About Mars - NASA's Mars Exploration Program", NASA's Mars Exploration Program Available: https://mars.nasa.gov/all-about- mars/facts/\#?c=inspace\&s=distance. [5] "Mars Exploration Rover Mission: Spotlight", Mars.nasa.gov Available: https://mars.nasa.gov/mer/spotlight/20070612.html.

[6] "Lithium titanate (LTO) battery pack manufacturer | Large Power| Large Power", Lithiumion- batterypack.com Available: http://www.lithiumion-batterypack.com/low-temperature- battery.html.

[7] Lamarre, O., and Kelly, J., "Overcoming the Challenges of Solar Rover Autonomy: Enabling Long-Duration Planetary Navigation", arXiv e-prints, 2018.

[8] Balaram, B., Canham, T., Duncan, C., Grip, H. F., Johnson, W., Maki, J., Quon, A., Stern, R., and Zhu, D., "Mars Helicopter Technology Demonstrator," 2018 AIAA Atmospheric Flight Mechanics Conference, January 2018, doi:10.2514/6.2018-0023.

[9] Lorenz R.D., Turtle E.P., Barnes J.W., Trainer M.G., Adams D.S., Hibbard K.E., Sheldon C.Z., Zacny K., Peplowski P.N., Lawrence D.J., Ravine M.A., McGee T.G., Sotzen K.S., MacKenzie S.M., Langelaan J.W., Schmitz S., Wolfarth L.S., Bedini P.D., "Dragonfly: a rotorcraft lander concept for scientific exploration at Titan,"2018 Johns Hopkins APL Technical Digest, Volume 34, Number 3 pp. 374-38 [10] MEPAG (2018), Mars Scientific Goals, Objectives, Investigations, and Priorities: 2018. D.

Banfield, ed., 81 p. white paper posted October, 2018 by the Mars Exploration Program Analysis Group (MEPAG) at https://mepag.jpl.nasa.gov/reports.cfm

[11] Grant, J. A., Golombek, M. P., Grotzinger, J. P., Wilson, S. A., Watkins, M. M., Vasavada, A. R., Griffes, J. L., and Parker, T. J., "The science process for selecting the landing site for the 2011 Mars Science Laboratory," Planetary and Space Science, Vol. 59, No. 11-12, 2011, pp. 1114-1127, doi: 10.1016/j.pss.2010.06.016.

[12] Farley, K. A., and Williford, K. H., "Mars 2020 landing site down-select," Received by Michael Meyer, 13 February 2017.

[13] Grant, J. A., Golombek, M. P., Wilson, S. A., Farley, K. A., Williford, K. H., and Chen, A., "The science process for selecting the landing site for the 2020 Mars rover," Planetary and Space Science, Vol. 164, Dec 2018, pp. 106-126, doi: 10.1016/j.pss.2018.07.001.

[14] Cushing, G. E., Titus, T. N., Wynne, J. J., and Christensen, P. R., "THEMIS observes possible cave skylights on Mars," Geophys. Res. Lett., Vol. 34, L17201, 2007, doi:

10.1029/2007GL030709.

[15] Léveillé, R. J., and Datta, S., "Lava tubes and basaltic caves as astrobiological targets on Earth and Mars: A review," Planetary and Space Science, Vol. 58, No. 4, 2010, pp. 592-598, doi: 10.1016/j.pss.2009.06.004.

[16] Williams, K.E., McKay, C. P., Toon, O.B., and Head, J. W., "Do ice caves exist on Mars?," Icarus, Vol. 209, No. 2, 2010, pp. 358-368, doi:10.1016/j.icarus.2010.03.039.

[17] NASA Mars 2020 Mission, "Mars 2020 Rover Depot Caching Strategy" Available: https://mars.nasa.gov/mars2020/mission/timeline/surface-operations/. 
[18] NASA Mars 2020 Mission, "Mars 2020 Mission Contributions to NASA's Mars Exploration Program Science Goal" Available: https://mars.nasa.gov/mars2020/mission/science/goals/\#mars2020-goal-1.

[19] Kumar, P. S., Krishna, N., Lakshmi, K. J. P., Raghukanth, S. T. G., Dhabu, A., and Platz, T., "Recent seismicity in Valles Marineris, Mars: Insights from young faults, landslides, boulder falls and possible mud volcanoes," Earth and Planetary Science Letters, Vol. 505, 2019, pp. 51- 64, doi: 10.1016/j.epsl.2018.10.008.

[20] Mangold, N., Quantin, C., Ansan, V., Delacourt, C., and Allemand, P., "Evidence for Precipitation on Mars from Dendritic Valleys in the Valles Marineris Area," Science, Vol. 305, No. 5680, July 2004, pp. 78-81 doi: 10.1126/science. 1097549

[21] Chu, P., Spring, J., and Zacny, K., "ROPEC - ROtary PErcussive Coring Drill for Mars Sample Return," Proceedings of the $42^{\text {nd }}$ Aerospace Mechanisms Symposium, NASA Goddard Space Flight Center, May 2014.

[22] Honeybee Robotics, "PlanetVac,” Available: https://honeybeerobotics.com/portfolio/planetvac/

[23] Honeybee Robotics, "Nano Drill,” Available: https://honeybeerobotics.com/portfolio/nano- drill/

[24] Chang, C., Wang, J., Chang, C., Liang, M., and Lin, M., "Development of a multicopter- carried whole air sampling apparatus and its applications in environmental studies", Chemosphere, Vol. 144, 2016, pp. 484-492. doi: 10.1016/j.chemosphere.2015.08.028

[25] R. Mattingly and L. May, "Mars Sample Return as a campaign," 2011 Aerospace

Conference, Big Sky, MT, 2011, pp. 1-13. doi: 10.1109/AERO.2011.5747287

[26] Mars Education at Arizona State University, "Polar Caps", Available https://marsed.asu.edu/mep/ice/polarcaps

[27] Roger J.P, et al., "Mars North Polar Deposits: Stratigraphy, Age, and Geodynamical Response," Science, Vol. 320, No. 5880, 2008, pp. 1182-1185, doi: 10.1126/science.1157546. [28] NASA, "North Polar Layers of

Mars", Available: https://www.nasa.gov/multimedia/imagegallery/image_feature_1731.html

[29] Chu, "Researchers calculate size of particle in Martian clouds of $\mathrm{CO} 2$ snow," Available: http://news.mit.edu/2012/co2-snow-on-mars-0619

[30] NASA, "Chasma Boreale,

Mars,” Available: https://www.nasa.gov/multimedia/imagegallery/image_feature_1894.html

[31] NASA Jet Propulsion Laboratory, "NASA Tests Robotic Ice

Tools," Available: https://www.jpl.nasa.gov/news/news.php?feature $=6801$

[32] Liu, T., Oyama, A., and Fujii, K., "Scaling Analysis of Propeller-Driven Aircraft for Mars Exploration", Journal of Aircraft, Vol. 50, No. 5, 2013, pp. 1593-1604. doi: 10.2514/1.c032086

[33] "E63 (4.25\%) (e63-il)", Airfoiltools.com Available: http://airfoiltools.com/airfoil/details?airfoil=e63-il. [34] Santos Fernandes, N., "Design and construction of a multi-rotor with various degrees of freedom", MS, Universidade Tecnica de lisboa, 2011.

[F1] Williams, D. (2019). Mars Fact Sheet. [online] Nssdc.gsfc.nasa.gov. Available at: https://nssdc.gsfc.nasa.gov/planetary/factsheet/marsfact.html [Accessed 29 Jul. 2019].

[F2] NASA, "Mars Helicopter to Fly on NASA's Next Red Planet Rover Mission,"

Available: https://www.nasa.gov/press-release/mars-helicopter-to-fly-on-nasa-s-next-red-planet- rover-mission

[F3] John Hopkins APL, Dragonfly moving between study sites on Titan, 2019.

Available: https://dragonfly.jhuapl.edu/Gallery/files/images/df-landing.png

[F4] NASA, "Valles Marineris," Available: https://mars.jpl.nasa.gov/gallery/atlas/valles- marineris.html 
[F5] NASA, “Tharsis Volcano,” Available: https://mars.nasa.gov/resources/7128/tharsis- volcano/

[F6] Honeybee Robotics, "ROPEC Drill,"

Available: https:/honeybeerobotics.com/portfolio/ropec-drill/

[F7] Honeybee Robotics, “Nano Drill,” Available: https://honeybeerobotics.com/portfolio/nano- drill/

[F8] Chang, C., Wang, J., Chang, C., Liang, M., and Lin, M., "Development of a multicopter- carried whole air sampling apparatus and its applications in environmental studies", Chemosphere, Vol. 144, 2016, pp. 484-492. doi: 10.1016/j.chemosphere.2015.08.028 [F9] NASA, "North Polar Layers of Mars,"

Available: https://www.nasa.gov/multimedia/imagegallery/image_feature_1731.html

[F10] NASA/JPL, "NASA Tests Robotic Ice Tools,"

Available: https://www.jpl.nasa.gov/news/news.php?feature $=6801$

[F11] NASA, “Cave Skylights Spotted On Mars,” Available: https://science.nasa.gov/sciencenews/scienceatnasa/2007/21sep_caves 